\title{
A Maternidade Afeta o Engajamento da Mulher no Mercado de Trabalho?: Um Estudo Utilizando o Nascimento de Gêmeos como um Experimento Natural ${ }^{\star}$
}

- Elaine Toldo PaZello*

\section{RESUMO}

O objetivo deste artigo foi analisar o impacto de um choque exógeno na fecundidade - nascimento de gêmeos na primeira gravidez - sobre o engajamento da mulher na força de trabalho. A hipótese assumida é que embora a decisão de ter filhos seja endógena, a ocorrência de gêmeos é um evento aleatório. Os resultados obtidos sugerem que um aumento não planejado no número de filhos tem efeito negativo apenas sobre a probabilidade de participação da mulher no mercado de trabalho, e mesmo assim apenas no curto prazo.

\section{PalavRAS-CHAVE}

gêmeos, oferta de trabalho feminina, fecundidade

\begin{abstract}
The purpose of this paper is to analyze the impact of an exogenous shock on fertility - using twin first birth - upon women's participation in the labor market. The assumption is that, even though the decision of having children is endogenous, twin birth is a random event. Results obtained suggest that unplanned increase in the number of children has a negative effect only on the probability of women's participation in the labor market. Moreover, this effect seems to be relevant just in the short run.
\end{abstract}

\section{KEY WORDS}

twin birth, woman labor supply, fertility

\section{JEL CLASSIFICATION}

$J 13, J 21, J 22$

\footnotetext{
+ A autora agradece a um parecerista anônimo por suas sugestões e, em especial, ao Prof. Reynaldo Fernandes que em muito contribuiu para a realização desta pesquisa.

* Departamento de Economia da FEA-RP/USP. E-mail: epazello@usp.br. Endereço para correspondência: Av. dos Bandeirantes, 3900 - FEA-RP / USP - Depto de Economia - Ribeirão Preto, SP - CEP: 14040-900 (Recebido em outubro de 2004. Aceito para publicação em janeiro de 2006).
} 


\section{INTRODUÇÃO}

O crescimento da participação da mulher no mercado de trabalho é um dos fatos empíricos mais bem evidenciados. Para se ter uma idéia, no Brasil, entre 1982 e 1997, a taxa de participação na força de trabalho das mulheres como um todo cresceu $35 \%$, sendo este crescimento ainda maior para os grupos de mulheres mais jovens e mais educadas. Nesta linha, diversos estudos têm procurado identificar os fatores determinantes deste novo comportamento da mulher. $\mathrm{O}$ aumento da qualificação profissional, entre outros, tem sido apontado como um elemento importante que tem contribuído de forma decisiva para a maior participação feminina no mercado de trabalho. ${ }^{1}$

O objetivo deste artigo é mensurar o impacto da maternidade sobre o engajamento da mulher no mercado de trabalho. O entendimento desta relação é importante por inúmeras razões. Primeiramente, a relação entre filhos e engajamento pode ajudar a explicar a maior participação da mulher no mercado de trabalho a partir dos anos 1950: um menor número de filhos ${ }^{2}$ estaria relacionado a um maior engajamento no mercado de trabalho. Em segundo lugar, o papel da maternidade sobre o engajamento da mulher no mercado de trabalho poderia ser um dos fatores que estaria explicando o diferencial de salário e de ocupações entre homens e mulheres, questão ainda em aberto na literatura. $\mathrm{O}$ interesse na relação entre filhos e engajamento também vem aumentando devido ao crescente número de modelos que relacionam família e mercado de trabalho e, dentro deste ferramental, o elo entre a participação da mãe e o número de filhos tem destaque. ${ }^{3}$

Medir o impacto da maternidade sobre o engajamento da mulher, no entanto, não é uma tarefa fácil. Não é correto tratar a maternidade e a estrutura familiar como determinantes exógenos do comportamento de oferta de trabalho da mulher. Isto porque as decisões sobre o número de filhos, bem como sobre quando se ter filhos, dependem de como a mulher está inserida no mercado de trabalho (ou seja, de suas características de mercado). Além disso, características não-observáveis - como, por exemplo, preferências por ter e/ou cuidar de filhos - afetam o número de filhos e o engajamento. A simples comparação do engajamento de uma mulher com filhos com o de outra sem filhos, ainda que esta comparação levasse em conta todas as características observáveis, provavelmente estaria enviesada.

l Para um survey de estudos empíricos sobre a oferta de trabalho feminina, ver Killingsworth e Heckman (1986). Para o Brasil, ver, entre outros, Scorzafave e Menezes-Filho (2001) e Soares e Izaki (2002).

2 A taxa de fecundidade diminuiu significativamente ao longo dos últimos anos. No Brasil, segundo dados do Censo Demográfico do IBGE, em 1970, uma mulher, em idade fértil, tinha em média 5,8 filhos; em 2002, este número caiu para 2, ou seja, uma redução de $60 \%$.

3 A composição etária dos filhos na família, por exemplo, deve influenciar as estimativas do trabalhador adicional (added work effect). 
O ideal para resolver este problema seria observar uma mesma mulher, em um mesmo momento do tempo, na condição de ter tido o filho e na condição de não ter tido o filho. Mas, como se sabe, isto não é factível. Uma solução possível, explorada por diversos estudos para os Estados Unidos, é utilizar a ocorrência de gêmeos, supondo tratar-se de uma variação exógena na fecundidade. A decisão de ter filhos seria endógena, mas a ocorrência de gêmeos seria um evento aleatório, por hipótese, não correlacionado com as características que determinam a participação da mulher no mercado de trabalho. ${ }^{4}$

Este exercício empírico já foi, como dito, realizado por outros autores. Em Rosenzweig e Wolpin (1980b), ${ }^{5}$ os autores estimam o impacto de uma variação exógena na fecundidade - obtida a partir da ocorrência de gêmeos - sobre a participação da mulher no mercado de trabalho ao longo do ciclo de vida. Um ponto importante notado pelos autores - e mantido nos artigos que vieram a seguir - é que os gêmeos têm de ser da primeira gravidez. Isto se deve a duas razões: $1^{\circ}$ ) mulheres com mais filhos - portanto, com maior preferência por filhos - são super-representadas em amostras de famílias de gêmeos. Assim, a oferta de trabalho de mães de gêmeos deve refletir, em parte, uma maior preferência por crianças; $2^{\circ}$ ) a probabilidade de ocorrência de gêmeos por parto aumenta com o número de vezes que a mulher engravida, e o número de vezes que a mulher engravida está certamente correlacionado com preferências não observadas a respeito do tamanho da família. Os resultados obtidos por esses autores indicam que mulheres mais jovens (entre 15 e 24 anos) que tiveram gêmeos na primeira gravidez têm uma menor probabilidade de participação no mercado de trabalho $(-0,371)$ em relação às mulheres que não tiveram gêmeos. No entanto, este impacto declina ao longo do tempo (-0,102 para mulheres com idade entre 25 e 34 anos) e chega a ter seu sinal invertido para mulheres com idade entre 35 e 44 anos $(0,142)$. Segundo os autores esta inversão do sinal coloca dúvidas sobre o impacto negativo que filhos teriam sobre o processo de acumulação de capital humano ao longo do ciclo de vida. Os autores trabalham com dados de pesquisas realizadas em 1965 (Office of Population Survey) e 1973 (U. S. Departament of Health, Education and Welfare).

Em Bronars e Grogger (1994), os autores utilizam a ocorrência de gêmeos para analisar o impacto (de curto e longo prazo) de um filho não planejado sobre as condições socioeconômicas de mães que na época do nascimento do filho eram não-casadas. As

4 A ocorrência de gêmeos pode não ser tão aleatória. O nascimento de gêmeos é comum em mulheres que se submetem a tratamentos hormonais em razão de dificuldades de engravidar. Provavelmente, as mulheres que fazem esses tratamentos possuem maiores rendimentos, visto que estes têm custo elevado. Porém, a porcentagem de mulheres que faz esses tratamentos ainda é pequena e, assim, teria pouco impacto em nosso estudo. Ainda que isso não seja verdade, se gêmeos for correlacionado apenas com variáveis observáveis (renda do marido, educação etc.) seria possível controlar este efeito.

5 O evento 'gêmeos' foi utilizado originalmente por esses mesmos autores em Rosenzweig e Wolpin (1980a). Nesse artigo, os autores testam empiricamente as hipóteses do modelo de fecundidade proposto por Becker e Lewis, que trata da interação das variáveis 'número de filhos' e 'qualidade dos filhos'. 
estimativas encontradas mostram que no curto prazo (quando a criança tem entre 0 e 3 anos) há um efeito negativo do filho extra sobre a participação no mercado de trabalho (em torno de $-0,114$ ), mas que no longo prazo (quando a criança tem entre 10 e 13 anos) este efeito desaparece $(-0,037)$. Resultados na mesma direção são também encontrados para a variável salário. Em se tratando da variável renda familiar, no entanto, os resultados encontrados apontam para um efeito econômico adverso persistente sobre mães negras. Os autores trabalham com dados de 1970 (Public Use Microdata Samples - PUMS) e 1980 (Censo).

Em Gangadharan e Rosenbloom (1996), o exercício realizado é o mesmo que em Bronars e Grogger, no entanto, os autores trabalham exclusivamente com mães que na época de nascimento dos filhos eram casadas. Em termos de participação no mercado de trabalho, Gangadharan e Rosenbloom encontram efeitos negativos no curto prazo (entre 0 e 2 anos do tempo de nascimento da criança): -0,0744 a partir dos dados do Censo de 1980 e -0,1309 a partir dos dados do Censo de 1990. Estes efeitos também desaparecem ao longo do tempo. Nesse artigo, os autores chamam atenção para os efeitos negativos sobre o salário encontrados para o ano de 1990: diferentemente do artigo de Bronars e Grogger, o impacto negativo do filho extra sobre os salários permanece no longo prazo. Os autores atribuem este resultado às maiores oportunidades de acumulação de capital humano e de avanço na carreira atualmente existentes para as mulheres que acabam por impor um custo maior, em termos de perda de rendimento, do filho não planejado.

E, por fim, mais recentemente, Angrist e Evans (1998) também utilizaram a ocorrência de gêmeos, como uma variação exógena no tamanho da família, para investigar a relação entre filhos e oferta de trabalho. No entanto, o trabalho destes autores é relativamente diferente. $\mathrm{Na}$ verdade, neste artigo os autores usam a preferência dos pais por uma composição mista de filhos ('um menino e uma menina') como instrumento para número de filhos. Isto é, existiria uma correlação positiva entre o nascimento de dois filhos de mesmo sexo e a ocorrência de um terceiro filho. Os autores comparam as estimativas de IV obtidas por este procedimento com as obtidas quando o instrumento é a ocorrência de gêmeos. Assim, diferentemente dos outros artigos, nesse caso só interessam aos autores gêmeos que ocorreram na segunda gravidez. ${ }^{6}$ As estimativas obtidas não diferenciam o curto prazo do longo prazo e, de forma geral, indicam um impacto negativo e significativo nos indicadores analisados.

Este artigo segue a mesma linha dos anteriores. O objetivo é avaliar o impacto de uma variação exógena no número de filhos (a partir da ocorrência de gêmeos) sobre o engajamento da mulher na força de trabalho (participação e jornada de trabalho) e

6 Por utilizarem gêmeos da segunda gravidez, os autores controlam as estimativas de IV pelas características das mães. 
sobre seus rendimentos. Utilizam-se aqui os dados da Pesquisa Nacional de Amostras por Domicílio no período entre 1992 e 1999. A contribuição do artigo, além do fato de trabalhar com dados para o Brasil, está em chamar atenção para o possível viés de seleção que pode surgir na análise das variáveis de mercado de trabalho (salário e jornada de trabalho). Como apenas uma parte das mães que tiveram gêmeos e das que não tiveram gêmeos trabalham, e como as mães de gêmeos têm mais filhos, pode ser que as mães de gêmeos que trabalham sejam mais produtivas do que as mães que não tiveram gêmeos. Os resultados encontrados parecem indicar a existência deste viés de seleção.

$\mathrm{O}$ artigo está dividido em quatro seções além desta introdução. A primeira e segunda seções descrevem, respectivamente, os dados e a metodologia. A terceira seção apresenta os resultados obtidos. A última seção é dedicada às observações finais.

\section{DADOS}

A base de dados utilizada é uma subamostra da Pesquisa Nacional de Amostras por Domicílio - PNAD - do IBGE, no período entre 1992 e 1999, com exceção do ano de 1994, quando a pesquisa não foi realizada. A princípio, foram incluídas na amostra todas as famílias ${ }^{7}$ que viviam na área urbana do País e que tinham pelo menos um membro da família na condição de filho. Buscando garantir a aleatoriedade da ocorrência de gêmeos, só interessou a este trabalho as mulheres que tiveram gêmeos na primeira gravidez. Para identificar a ocorrência de gêmeos entre essas famílias, foram utilizadas as variáveis dia, mês e ano de nascimento dos filhos. Ou seja, se a data de nascimento do filho mais velho era exatamente igual à data de nascimento do segundo filho mais velho, então esta mãe foi incluída na amostra de mães que tiveram gêmeos. Caso contrário foi incluída na amostra de mães que não tiveram gêmeos.

Para garantir que os gêmeos eram da primeira gravidez da mãe, optou-se por excluir as famílias cujas mães tinham mais de quarenta anos de idade. O objetivo deste procedimento é minimizar a possibilidade de se trabalhar com mães que tenham filhos morando em outros domicílios, visto que, neste caso, o filho identificado na entrevista da PNAD como sendo o mais velho não seria, de fato, o mais velho. Além disto, foram excluídas as famílias cuja diferença entre a idade da suposta mãe e a idade do filho mais velho era inferior a 14. Isto foi feito para garantir que o componente da família identificado como filho era efetivamente filho do casal ou do chefe quando o cônjuge não estava presente. Feitos estes filtros, obteve-se ao final, para o conjunto dos sete anos, um total de 1.033 mães de gêmeos e 194.903 mães de não-gêmeos.

7 Não foram incluídas aquelas famílias que dividem o domicílio com outra(s) família(s). 
A Tabela 1 apresenta os valores médios e desvio padrão para um conjunto de variáveis demográficas e econômicas para as mães de gêmeos e mães de não-gêmeos.

TABELA I - DESCRIÇÃO DAS CARACTERÍSTICAS OBSERVÁVEIS DAS $M \tilde{A E S}$

\begin{tabular}{|c|c|c|c|c|c|c|c|c|}
\hline $\begin{array}{l}\text { Grupos } \\
\text { Variáveis }\end{array}$ & Mães de ... & 1992 & 1993 & 1995 & 1996 & 1997 & 1998 & 1999 \\
\hline \multirow{4}{*}{ Idade } & Gêmeos & 31 & 31 & 31 & 32 & 32 & 32 & 32 \\
\hline & & (5) & (6) & (6) & (6) & (6) & (6) & (5) \\
\hline & Não-gêmeos & 31 & 31 & 31 & 31 & 31 & 31 & 31 \\
\hline & & (6) & (6) & (6) & (6) & (6) & (6) & (6) \\
\hline \multirow{4}{*}{ Anos de Estudo } & Gêmeos & 7.72 & 6.73 & 7.27 & 7.42 & 7.68 & 7.70 & 7.60 \\
\hline & & $(4.38)$ & $(4.05)$ & $(4.09)$ & $(3.94)$ & $(3.88)$ & $(4.03)$ & $(4.06)$ \\
\hline & Não-gêmeos & 6.44 & 6.56 & 6.65 & 6.82 & 6.91 & 7.03 & 7.17 \\
\hline & & $(4.11)$ & $(4.08)$ & $(4.04)$ & $(4.01)$ & $(4.03)$ & $(4.00)$ & (3.96) \\
\hline \multirow{4}{*}{$\begin{array}{l}\text { Número de } \\
\text { Filhos }\end{array}$} & Gêmeos & 2.82 & 2.96 & 2.58 & 2.69 & 2.70 & 2.56 & 2.58 \\
\hline & & $(1.12)$ & $(1.24)$ & $(0.84)$ & $(0.90)$ & $(1.04)$ & $(0.79)$ & $(0.76)$ \\
\hline & Não-gêmeos & 2.31 & 2.27 & 2.23 & 2.19 & 2.16 & 2.13 & 2.10 \\
\hline & & $(1.29)$ & $(1.26)$ & (1.21) & $(1.18)$ & $(1.16)$ & $(1.14)$ & (1.12) \\
\hline \multirow{4}{*}{$\begin{array}{l}\text { Idade do filho + } \\
\text { velho }\end{array}$} & Gêmeos & 7.38 & 8.45 & 8.10 & 8.17 & 7.88 & 7.84 & 7.92 \\
\hline & & $(5.07)$ & $(5.40)$ & $(5.25)$ & $(5.44)$ & $(5.51)$ & $(5.52)$ & (5.34) \\
\hline & Não-gêmeos & 8.84 & 8.91 & 9.13 & 9.25 & 9.24 & 9.25 & 9.25 \\
\hline & & (5.52) & (5.53) & $(5.55)$ & (5.59) & (5.59) & $(5.62)$ & (5.60) \\
\hline \multirow{4}{*}{$\begin{array}{l}\text { Sal_hora do } \\
\text { trab. Princ. }{ }^{1}\end{array}$} & Gêmeos & 6.17 & 4.26 & 6.64 & 8.94 & 6.78 & 8.95 & 7.64 \\
\hline & & (13.79) & $(9.04)$ & (15.14) & (31.54) & (12.32) & $(20.05)$ & (18.01) \\
\hline & Não-gêmeos & 4.13 & 4.22 & 6.14 & 6.64 & 6.33 & 6.06 & 5.83 \\
\hline & & (10.63) & (17.92) & (15.52) & (42.28) & (20.45) & (15.90) & (16.64) \\
\hline \multirow{4}{*}{$\begin{array}{l}\text { Jornada de } \\
\text { trabalho }^{1}\end{array}$} & Gêmeos & 36.73 & 35.90 & 37.36 & 38.27 & 35.51 & 36.82 & 36.05 \\
\hline & & $(15.55)$ & (14.29) & (14.49) & (15.36) & (12.95) & (14.15) & (13.63) \\
\hline & Não-gêmeos & 35.50 & 35.58 & 36.16 & 37.11 & 37.05 & 37.55 & 37.12 \\
\hline & & $(15.82)$ & (15.53) & $(15.46)$ & $(15.86)$ & $(15.62)$ & (15.77) & (15.66) \\
\hline \multirow{4}{*}{ Renda familiar } & Gêmeos & 913.6 & 906.1 & 1003.9 & 1255.1 & 1049.0 & 1266.6 & 1007.9 \\
\hline & & (1216.4) & $(1452.0)$ & (2038.2) & $(2885.4)$ & $(974.4)$ & (1917.4) & (1298.0) \\
\hline & Não-gêmeos & 722.5 & 718.6 & 1010.7 & 1001.8 & 990.8 & 951.5 & 890.2 \\
\hline & & (1041.9) & $(1778.4)$ & (1498.5) & $(1441.8)$ & (1567.3) & $(1395.0)$ & (1304.0) \\
\hline \multirow{2}{*}{$\mathrm{N}^{0}$ de Obs. } & Gêmeos & 154 & 140 & 154 & 132 & 164 & 135 & 154 \\
\hline & Não-gêmeos & 26805 & 27479 & 28044 & 27131 & 28550 & 28169 & 28725 \\
\hline
\end{tabular}

* Desvio padrão das variáveis entre parênteses.

1. Os cálculos de média e desvio padrão dessa variável consideram apenas as mães ocupadas. 
Um fato que chama atenção na Tabela 1 é que embora as mães de gêmeos tenham, em média, um número maior de filhos, a idade do seu filho mais velho é menor do que a idade do filho mais velho das mães que não tiveram gêmeos. Relacionando isto com a evidência de que as mães de gêmeos têm, em média, a mesma idade das mães de não-gêmeos, pode-se concluir que as mães de gêmeos têm filhos numa fase mais avançada do seu ciclo de vida. Um outro ponto é que as mães de gêmeos são, em média, mais educadas, o que se reflete em mais altos níveis salariais.

Essa evidência empírica de que as mães de gêmeos são mais educadas pode estar indicando que a ocorrência de gêmeos não seja tão aleatória. Mulheres mais produtivas, em geral, tendem a atrasar a gravidez, o que acaba por aumentar a probabilidade de nascimento de gêmeos. A observação, também apontada na Tabela 1 , de que as mães de gêmeos de fato têm filhos mais tarde corrobora esta hipótese. Em vista disto, nos exercícios empíricos realizados no artigo este controle (isto é, da escolaridade) será levado em consideração.

A Tabela 2 apresenta a distribuição geográfica, racial, de status marital e por condição de atividade e de ocupação das mães de gêmeos e de não-gêmeos.

TABELA 2 - DISTRIBUIÇÃO DAS MÃES SEGUNDO CRITÉRIOS DE REGIÃO, DE RAÇA, DE STATUS MARITAL E DE ENGAJAMENTO NO MERCADO DE TRABALHO

\begin{tabular}{lcc}
\hline Variáveis & Mães de Gêmeos & Mães de Não-Gêmeos \\
\hline Norte & $6.97 \%$ & $8.15 \%$ \\
Nordeste & $21.97 \%$ & $25.71 \%$ \\
Sudeste & $41.14 \%$ & $35.25 \%$ \\
Sul & $17.42 \%$ & $18.76 \%$ \\
Centro-Oeste & $12.49 \%$ & $12.12 \%$ \\
\hline Metropolitana & $45.21 \%$ & $45.28 \%$ \\
\hline Branca & $58.60 \%$ & $55.77 \%$ \\
\hline Cônjuge Presente & $89.25 \%$ & $89.22 \%$ \\
\hline Ativa & $55.33 \%$ & $55.96 \%$ \\
\hline Ocupada & $92.64 \%$ & $89.47 \%$ \\
\hline No de observ. & 1033 & 194.903 \\
\hline
\end{tabular}

* Valores expressos são as médias do período estudado (entre 1992 e 1999). 
As distribuições acima são bastante semelhantes. Dessa tabela, o que chama atenção é a maior concentração de mães brancas entre as que tiveram gêmeos e também o fato de a taxa de desemprego ser relativamente menor entre as mães de gêmeos.

\section{METODOLOGIA}

Como colocado inicialmente o objetivo deste artigo é investigar o impacto de uma variação exógena na fecundidade sobre o engajamento da mulher no mercado de trabalho. O fato de a mulher ser a principal responsável pelos cuidados com filhos pequenos ${ }^{8}$ acaba por fazer com que muitas saiam integralmente do mercado de trabalho ou então passem a trabalhar apenas em turnos parciais ou em empregos de jornadas mais flexíveis, quando têm seus filhos. Esta saída pode prejudicar o processo de acumulação de capital humano da mulher, tendo, inclusive, impactos negativos sobre seus rendimentos esperados futuros.

Como não é possível observar uma mesma mulher com filho e sem filho, e como a randomização neste caso não parece uma boa idéia, uma solução possível é utilizar a ocorrência de gêmeos, visto que este evento representa uma variação exógena no número de filhos.

$\mathrm{O}$ artigo quer medir o impacto do número de filhos sobre o engajamento da mulher na força de trabalho. Formalmente:

$$
Y_{i}=\alpha+\gamma N_{i}+v_{i}
$$

em que $Y$ é a variável de interesse (participação no mercado de trabalho, jornada de trabalho e salário) e $N$ é o número de filhos.

No entanto, se esta equação for estimada por MQO, o coeficiente $\gamma$ será enviesado, pois certamente $E\left(v_{i} / N_{i}\right) \neq 0$. A inclusão de controles observáveis (educação, idade, região etc.) é uma possível estratégia. Mas, mesmo assim, é difícil acreditar que tais variáveis captem toda a correlação entre os regressores e os fatores não observáveis. Certamente, existe alguma característica não observável - por exemplo, preferência por cuidar dos filhos - que influencia a mulher tanto em sua opção de ter filhos como de quantos filhos ter, que é correlacionada com a probabilidade de participação e/ou com a jornada de trabalho e/ou com o salário, que não está sendo considerada. Ou seja, na equação (1) acima, a variação no número de filhos é endógena.

8 Aqui se pode pensar que é uma questão de preferência: as mulheres preferem ficar com seus filhos a irem para o mercado de trabalho. 
No caso de gêmeos, a variação no número de filhos é exógena, não planejada. Se acreditarmos que a ocorrência de gêmeos é totalmente aleatória, isto é, não-correlacionada com qualquer outra característica individual produtiva da mulher (observável ou não-observável), podemos simplesmente estimar:

$$
Y_{i}=\alpha+\beta G_{i}+u_{i}
$$

em que $G$ é uma variável que assume valor 1 no caso na mulher ter tido gêmeos na primeira gravidez. Para que a hipótese de identificação $\left\{E\left(u_{i} / G_{i}\right)=0\right\}$ seja válida, é necessário controlar pela idade da mulher na época de nascimento da criança, visto que a probabilidade de ocorrência de gêmeos aumenta com a idade com que a mulher tem seu primeiro filho. Em mulheres mais velhas, a ovulação tende a se tornar mais irregular, o que se por um lado aumenta a probabilidade de nascimentos de gêmeos, também pode gerar mais dificuldades para que ela engravide. Em decorrência disto, mais comumente essas mulheres se submetem a tratamentos hormonais, os quais, por sua vez, aumentam a probabilidade de nascimento de gêmeos.

Na seção 1 foram encontradas evidências de que as mães de gêmeos são mais educadas que as mães de não-gêmeos. Por ser a variável educação um dos principais determinantes da renda, e como existe uma preocupação com uma possível não-aleatoriedade do evento 'gêmeos', achou-se por bem condicionar as estimativas também a este controle. Assim, a equação estimada foi:

$$
Y_{i}=\alpha+\beta_{1} I_{i}+\beta_{2} I 2_{i}+\beta_{3} G_{i}+\beta_{4} E d u c a+v_{i}
$$

em que:

$\mathrm{I}=$ idade em que a mulher teve o filho;

$\mathrm{I} 2$ = quadrado da idade em que a mulher teve o filho; e

Educa $=$ anos completos de estudo da mulher.

É interessante observar que o exercício empírico não está trabalhando com o evento gêmeos na forma de instrumento, ou seja, a dummy 'gêmeos' entra diretamente na equação, como descrito em (3). Quando se faz isso, o efeito captado é o do total de filhos. Se a variável 'gêmeos' fosse utilizada como instrumento para a variável 'número de filhos’, o efeito captado seria por filho. ${ }^{9}$ Para a estimação do efeito de gêmeos sobre

9 Angrist e Evans (1998) mostram que o coeficiente do impacto do número de filhos, instrumentalizado por gêmeos, sobre o salário, por exemplo, é igual a razão entre o $\beta^{\mathrm{MQO}}$ da equação na qual o salário é a variável dependente e o $\beta^{\mathrm{M} Q \mathrm{O}}$ da equação na qual o número de fillhos é a variável dependente. 
a probabilidade de participação assumiu-se que esta fosse descrita por uma função logística.

Um ponto que deve ser destacado é que ter gêmeos não é a mesma coisa que ter dois filhos em idades diferentes. No curto prazo, deve existir uma deseconomia de escala, o que pode levar a uma superestimação do impacto do filho não-planejado sobre o engajamento da mulher no mercado de trabalho. Em outras palavras, em parte o que estaria sendo medido seria o efeito próprio de ter gêmeos sobre a participação no mercado de trabalho. Assim, é interessante ler os resultados obtidos por este trabalho como um limite superior do possível impacto do fillho não-planejado.

No caso do impacto da ocorrência de gêmeos sobre jornada e salário de mercado da mulher existe uma dificuldade adicional. No caso da probabilidade de participação, todas as mulheres que fazem parte da amostra de mães entram na estimação. No entanto, nos casos de jornada e salários, só participarão das estimativas aquelas mulheres que têm horas trabalhadas e/ou remuneração positivas, ou seja, apenas uma parte das mães que tiveram gêmeos e apenas uma parte das mães que não tiveram gêmeos. Dada a evidência empírica de que as mães de gêmeos têm mais filhos, e como existe uma correlação negativa entre filhos e engajamento da mulher no mercado de trabalho, é possível que as mães de gêmeos que estão no mercado de trabalho sejam melhores em características não-observáveis do que as mães de não-gêmeos. A possível existência deste viés de seleção derruba a hipótese de identificação anteriormente descrita. Vale ressaltar que nenhum dos artigos anteriores que utilizaram a ocorrência de gêmeos para investigar a relação entre maternidade e oferta de trabalho da mulher levou em conta este problema.

Para corrigir este possível viés de seleção utilizou-se o processo de estimação proposto por Heckman, que trata a censura como um problema de variável omitida. ${ }^{10}$ A idéia básica é a seguinte: existem características não-observáveis que fazem com que algumas mães estejam trabalhando e outras não. E, muito provavelmente, estas características são correlacionadas com as características que determinam a jornada ou salário de mercado destas mães. Assim, se ignorarmos o processo de seleção, teremos estimativas enviesadas e inconsistentes da variável de interesse $\left(G_{i}\right)$.

As variáveis incluídas na estimativa da equação de seleção foram: anos de estudo, idade em que a mulher teve o filho, quadrado da idade em que a mulher teve o filho, quatro dummies para as macrorregiões (Sudeste é a referência), uma dummy para área metropolitana; seis dummies para os diferentes anos da PNAD (o ano de 1999 é a referência); uma dummy para raça (igual a 1 se a mulher é branca); uma dummy para gêmeos; e a renda do não-trabalho (renda familiar - salário da mulher). As variáveis

10 Heckman (1979). 
incluídas na equação principal (as variáveis dependentes são os logaritmos das variáveis de interesse, isto é, o log da jornada de trabalho e o log do salário) foram idênticas às incluídas na estimativa da equação de seleção, com exceção da variável renda do não-trabalho.

Ou seja, a renda do não-trabalho é a variável utilizada para identificar o processo de seleção. Por hipótese, esta renda não estaria correlacionada com as variáveis não-observáveis que determinam horas trabalhadas e salário da mulher no mercado de trabalho, mas estaria correlacionada com sua participação, visto que quanto maior a renda, menos necessária seria a renda obtida pela mulher no mercado de trabalho e, assim, menor a probabilidade de a mulher estar no mercado de trabalho. Na verdade, o uso da renda do não-trabalho como instrumento é mais defensável para o salário-hora do que para a jornada de trabalho. Pode-se pensar que uma maior renda do não-trabalho, levaria a mulher a trabalhar menos horas. ${ }^{11}$

\section{RESULTADOS}

Antes de explorarmos o impacto dos gêmeos sobre o engajamento e salário da mulher no mercado de trabalho é interessante ver a natureza deste choque exógeno. É de se esperar que as famílias que tenham tido gêmeos na primeira gravidez ajustem esta variação exógena da fecundidade no longo prazo. Assim, é de se esperar que no curto prazo o evento dos gêmeos tenha um efeito significativo sobre o número de filhos (por definição, próximo de um), mas que no longo prazo este efeito diminua.

Para examinar este efeito, estimou-se a seguinte regressão, por Mínimos Quadrados Ordinário: $N_{i}=\alpha+\beta_{1} I_{i}+\beta_{2} I 2_{i}+\beta_{3} G_{i}+\beta_{4} E d u c a+u_{i}$. Toda a argumentação desenvolvida na seção anterior a respeito da exogeneidade de $G_{i}$ na estimação da equação de participação também se aplica ao presente caso. Isto é, também aqui $E\left(u_{i} / G_{i}\right)=0$. As

Tabelas $3 \mathrm{a}$ e $3 \mathrm{~b}$ apresentam os resultados das estimativas, primeiramente para uma amostra onde apenas mães casadas são incluídas e, em seguida, para uma amostra que inclui todas as mães. O tipo de arranjo familiar deve influenciar as decisões da mulher quanto ao seu engajamento no mercado de trabalho. Por esta razão, optou-se por realizar estimativas separadas para as mães casadas. ${ }^{12}$

11 Pode-se argumentar que também para o salário, a renda do não-trabalho apresente problemas em razão da correlação entre as características produtivas das mulheres e as de seus cônjuges.

12 Na PNAD̉ não é possível identificar o estado cível dos indivíduos, assim, 'casada' significa que havia cônjuge no domicílio. 
TABELA 3a-IMPACTO DA OCORRÊNCIA DE GÊMEOS SOBRE O NÚMERO DE FILHOS - MÃES CASADAS

\begin{tabular}{|c|c|c|c|c|c|}
\hline \multirow[t]{2}{*}{ Número de Filhos } & \multicolumn{4}{|c|}{ Considerando-se apenas mães que tiveram filhos... } & \multirow[t]{2}{*}{ Total } \\
\hline & $\begin{array}{l}\text { Há } 2 \text { anos ou } \\
\text { menos } \\
\text { (curto-prazo) }\end{array}$ & $\begin{array}{l}\text { Entre } 3 \text { e } 6 \\
\text { anos }\end{array}$ & $\begin{array}{l}\text { Entre } 7 \text { e } 12 \\
\text { anos }\end{array}$ & $\begin{array}{l}\text { Há } 13 \text { anos ou } \\
\text { mais (longo- } \\
\text { prazo) }\end{array}$ & \\
\hline \multirow[t]{2}{*}{ Gêmeos } & 0,9944 & 0,7658 & 0,5162 & 0,5122 & 0,6531 \\
\hline & $(0,0258)$ & $(0,0413)$ & $(0,0466)$ & $(0,0836)$ & $(0,0305)$ \\
\hline \multirow[t]{2}{*}{1992} & 0,0244 & 0,1003 & 0,2058 & 0,4224 & 0,1721 \\
\hline & $(0,0079)$ & $(0,0132)$ & $(0,0148)$ & $(0,0227)$ & $(0,0102)$ \\
\hline \multirow[t]{2}{*}{1993} & 0,0201 & 0,0756 & 0,1649 & 0,3327 & 0,1359 \\
\hline & $(0,0079)$ & $(0,0132)$ & $(0,0144)$ & $(0,0219)$ & $(0,0099)$ \\
\hline \multirow[t]{2}{*}{1995} & 0,0188 & 0,0431 & 0,1100 & 0,2221 & 0,1043 \\
\hline & $(0,0080)$ & $(0,0130)$ & $(0,0144)$ & $(0,0207)$ & $(0,0097)$ \\
\hline \multirow[t]{2}{*}{1996} & 0,0200 & 0,0396 & 0,0499 & 0,1327 & 0,0714 \\
\hline & $(0,0080)$ & $(0,0132)$ & $(0,0143)$ & $(0,0207)$ & $(0,0096)$ \\
\hline \multirow[t]{2}{*}{1997} & 0,0164 & 0,0278 & 0,0301 & 0,1208 & 0,0518 \\
\hline & $(0,0079)$ & $(0,0131)$ & $(0,0140)$ & $(0,0203)$ & $(0,0095)$ \\
\hline \multirow[t]{2}{*}{1998} & 0,0151 & 0,0142 & 0,0170 & 0,0687 & 0,0281 \\
\hline & $(0,0079)$ & $(0,0130)$ & $(0,0142)$ & $(0,0201)$ & $(0,0094)$ \\
\hline \multirow[t]{2}{*}{ idade que teve o filho } & $-0,0116$ & $-0,0351$ & $-0,0519$ & $-0,0042$ & $-0,0442$ \\
\hline & $(0,0034)$ & $(0,0065)$ & $(0,0102)$ & $(0,0257)$ & $(0,0048)$ \\
\hline \multirow{2}{*}{$\begin{array}{l}\text { quadrado da idade que teve } \\
\text { o filho }\end{array}$} & 0,0002 & 0,0003 & 0,0002 & $-0,0019$ & $-0,0004$ \\
\hline & $(0,0001)$ & $(0,0001)$ & $(0,0002)$ & $(0,0006)$ & $(0,0001)$ \\
\hline \multirow[t]{2}{*}{ anos de estudo } & $-0,0095$ & $-0,0243$ & $-0,0455$ & $-0,0846$ & $-0,0587$ \\
\hline & $(0,0006)$ & $(0,0010)$ & $(0,0010)$ & $(0,0015)$ & $(0,0007)$ \\
\hline \multirow[t]{2}{*}{ Constante } & 1,3789 & 2,4903 & 3,6186 & 4,1985 & 3,6937 \\
\hline & $(0,0421)$ & $(0,0791)$ & $(0,1168)$ & $(0,2653)$ & $(0,0589)$ \\
\hline $\mathrm{N}^{0}$ de observações & 26.514 & 39.654 & 58.666 & 49.946 & 174.780 \\
\hline $\begin{array}{l}N^{0} \text { de observações de mães } \\
\text { de gêmeos }\end{array}$ & 171 & 240 & 299 & 211 & 921 \\
\hline$F(k, n-1-k)$ & 192,94 & 242,73 & 598,05 & 636,76 & $3.006,34$ \\
\hline Prob $>$ F & 0,000 & 0,000 & 0,000 & 0,000 & 0,000 \\
\hline R-quadrado & 0,0629 & 0,0563 & 0,0924 & 0,1121 & 0,1211 \\
\hline
\end{tabular}

Desvio padrão robusto entre parênteses. 
TABELA 3b - IMPACTO DA OCORRÊNCIA DE GÊMEOS SOBRE O NÚMERO DE FILHOS - TODAS AS MAEES

\begin{tabular}{|c|c|c|c|c|c|}
\hline \multirow[t]{2}{*}{ Número de Filhos } & \multicolumn{4}{|c|}{ Considerando-se apenas mães que tiveram filhos... } & \multirow[t]{2}{*}{ Total } \\
\hline & $\begin{array}{l}\text { Há } 2 \text { anos ou } \\
\text { menos } \\
\text { (curto-prazo) }\end{array}$ & $\begin{array}{c}\text { Entre } 3 \text { e } 6 \\
\text { anos }\end{array}$ & $\begin{array}{c}\text { Entre } 7 \text { e } 12 \\
\text { anos }\end{array}$ & $\begin{array}{c}\text { Há } 13 \text { anos ou } \\
\text { mais (longo- } \\
\text { prazo) }\end{array}$ & \\
\hline \multirow[t]{2}{*}{ gêmeos } & 0,9935 & 0,7629 & 0,5376 & 0,5035 & 0,6432 \\
\hline & $(0,0241)$ & $(0,0380)$ & $(0,0449)$ & $(0,0773)$ & $(0,0287)$ \\
\hline \multirow[t]{2}{*}{1992} & 0,0231 & 0,0967 & 0,2051 & 0,4161 & 0,1736 \\
\hline & $(0,0077)$ & $(0,0126)$ & $(0,0140)$ & $(0,0210)$ & $(0,0096)$ \\
\hline \multirow[t]{2}{*}{1993} & 0,0191 & 0,0774 & 0,1593 & 0,3366 & 0,1423 \\
\hline & $(0,0076)$ & $(0,0127)$ & $(0,0137)$ & $(0,0201)$ & $(0,0094)$ \\
\hline \multirow[t]{2}{*}{1995} & 0,0173 & 0,0464 & 0,1068 & 0,2232 & 0,1071 \\
\hline & $(0,0077)$ & $(0,0125)$ & $(0,0136)$ & $(0,0190)$ & $(0,0091)$ \\
\hline \multirow[t]{2}{*}{1996} & 0,0182 & 0,0402 & 0,0514 & 0,1334 & 0,0741 \\
\hline & $(0,0078)$ & $(0,0126)$ & $(0,0135)$ & $(0,0189)$ & $(0,0091)$ \\
\hline \multirow[t]{2}{*}{1997} & 0,0144 & 0,0251 & 0,0273 & 0,1210 & 0,0530 \\
\hline & $(0,0076)$ & $(0,0124)$ & $(0,0132)$ & $(0,0186)$ & $(0,0089)$ \\
\hline \multirow[t]{2}{*}{1998} & 0,0130 & 0,0145 & 0,0103 & 0,0617 & 0,0262 \\
\hline & $(0,0076)$ & $(0,0124)$ & $(0,0133)$ & $(0,0184)$ & $(0,0088)$ \\
\hline \multirow[t]{2}{*}{ idade que teve o filho } & $-0,0119$ & $-0,0361$ & $-0,0499$ & $-0,0077$ & $-0,0492$ \\
\hline & $(0,0032)$ & $(0,0062)$ & $(0,0097)$ & $(0,0235)$ & $(0,0045)$ \\
\hline \multirow{2}{*}{$\begin{array}{l}\text { quadrado da idade que teve } \\
\text { o filho }\end{array}$} & 0,0002 & 0,0003 & 0,0001 & $-0,0018$ & $-0,0003$ \\
\hline & $(0,0001)$ & $(0,0001)$ & $(0,0002)$ & $(0,0006)$ & $(0,0001)$ \\
\hline \multirow[t]{2}{*}{ anos de estudo } & $-0,0091$ & $-0,0244$ & $-0,0465$ & $-0,0845$ & $-0,0591$ \\
\hline & $(0,0006)$ & $(0,0009)$ & $(0,0010)$ & $(0,0014)$ & $(0,0007)$ \\
\hline \multirow[t]{2}{*}{ constante } & 1,3823 & 2,5064 & 3,5991 & 4,1712 & 3,7659 \\
\hline & $(0,0402)$ & $(0,0754)$ & $(0,1106)$ & $(0,2431)$ & $(0,0555)$ \\
\hline $\mathrm{N}^{0}$ de observações & 28076 & 42989 & 65720 & 59102 & 195887 \\
\hline $\begin{array}{l}\text { № de observações de mãe } \\
\text { de gêmeos }\end{array}$ & 188 & 274 & 329 & 242 & 1032 \\
\hline$F(k, n-1-k)$ & 217,06 & 290,19 & 709,18 & 745,08 & 3520,5 \\
\hline Prob $>F$ & 0,0000 & 0,0000 & 0,0000 & 0,0000 & 0,0000 \\
\hline R-quadrado & 0,0653 & 0,0612 & 0,0974 & 0,1111 & 0,125 \\
\hline
\end{tabular}

Desvio padrão robusto entre parênteses. 
Como era de se esperar, a ocorrência de gêmeos tem um impacto muito expressivo no curto prazo, mas que diminui ao longo do tempo. No entanto, mesmo no longo prazo as estatísticas parecem indicar que algum efeito permanece: mães que tiveram gêmeos na primeira gravidez têm, em média, 0,5 filho a mais do que mães que não tiveram gêmeos. ${ }^{13}$

Com relação às demais variáveis, os sinais são os esperados. As dummies de anos são todas positivas, indicando a queda da fecundidade ao longo do tempo (lembre-se que a dummy para o ano de 1999 é a referência). Há, inicialmente, uma relação negativa entre a 'idade em que a mãe teve o filho' e o 'número de filhos', algo razoável se pensarmos que as mulheres que postergam a gravidez têm um menor tempo hábil para ter filhos. No entanto, o sinal positivo da variável 'idade em que teve o filho ao quadrado' indica que a partir de uma certa idade esta relação torna-se positiva. Este comportamento pode estar refletindo justamente o fato de que a probabilidade de ocorrência de múltiplos filhos (gêmeos, trigêmeos etc.) aumenta com a idade da mulher. E, por fim, a variável 'anos de estudo', que indica que quanto maior a escolaridade da mulher menor o número de filhos, resultado conhecido na literatura. Praticamente não há diferenças entre os resultados que incluem apenas mães casadas e aqueles que incluem todas as mães.

A adição de uma criança a mais na família deve aumentar o montante de serviços relacionados a cuidados com o bebê e com a casa requeridos pela família, demandando, assim, uma presença mais efetiva da mulher dentro de casa, pelo menos no período imediatamente após o nascimento da criança. E qual o efeito desta realocação do tempo da mulher sobre seu engajamento no mercado de trabalho? As Tabelas 4a e $4 \mathrm{~b}$ apresentam o impacto da ocorrência de gêmeos (variação exógena no número de filhos) sobre a probabilidade de participação. Os números apresentados são os efeitos marginais calculados para a mulher de características médias.

13 Os resultados de Gangadharan e Rosenbloom (1996) são semelhantes aos deste artigo. Rosenzweig e Wolpin (1980), no entanto, encontraram que a incidência de gêmeos tem impacto negligenciável no tamanho da família no longo prazo. 
TABELA 4a - IMPACTO DA OCORRENCIA DE GEMEOS SOBRE A PROBABILIDADE DE PARTICIPAÇÃO DA MULHER NO MERCADO DE TRABALHO - APENAS AS MÃES CASADAS

\begin{tabular}{|c|c|c|c|c|c|}
\hline \multirow[b]{2}{*}{$\begin{array}{l}\text { Probabilidade de participar } \\
\text { do mercado de trabalho }\end{array}$} & \multicolumn{4}{|c|}{ Considerando-se apenas mães que tiveram filhos... } & \multirow[t]{2}{*}{ Total } \\
\hline & $\begin{array}{l}\text { Há } 2 \text { anos ou } \\
\text { menos } \\
\text { (curto-prazo) }\end{array}$ & $\begin{array}{c}\text { Entre } 3 \text { e } 6 \\
\text { anos }\end{array}$ & $\begin{array}{c}\text { Entre } 7 \text { e } 12 \\
\text { anos }\end{array}$ & $\begin{array}{c}\text { Há } 13 \text { anos ou } \\
\text { mais (longo- } \\
\text { prazo) }\end{array}$ & \\
\hline \multirow[t]{2}{*}{ gêmeos } & $-0,0776$ & $-0,0378$ & 0,0236 & 0,0208 & $-0,0127$ \\
\hline & $(0,0358)$ & $(0,0333)$ & $(0,0286)$ & $(0,0339)$ & $(0,0168)$ \\
\hline \multirow[t]{2}{*}{1992} & $-0,0621$ & $-0,0407$ & $-0,0562$ & $-0,0378$ & $-0,0530$ \\
\hline & $(0,0114)$ & $(0,0097)$ & $(0,0080)$ & $(0,0086)$ & $(0,0046)$ \\
\hline \multirow[t]{2}{*}{1993} & $-0,0626$ & $-0,0576$ & $-0,0500$ & $-0,0296$ & $-0,0516$ \\
\hline & $(0,0115)$ & $(0,0095)$ & $(0,0079)$ & $(0,0085)$ & $(0,0046)$ \\
\hline \multirow[t]{2}{*}{1995} & $-0,0280$ & $-0,0159$ & $-0,0218$ & $-0,0128$ & $-0,0197$ \\
\hline & $(0,0118)$ & $(0,0097)$ & $(0,0079)$ & $(0,0083)$ & $(0,0045)$ \\
\hline \multirow[t]{2}{*}{1996} & $-0,0421$ & $-0,0347$ & $-0,0443$ & $-0,0312$ & $-0,0367$ \\
\hline & $(0,0118)$ & $(0,0098)$ & $(0,0080)$ & $(0,0083)$ & $(0,0046)$ \\
\hline \multirow[t]{2}{*}{1997} & $-0,0373$ & $-0,0133$ & $-0,0294$ & $-0,0193$ & $-0,0240$ \\
\hline & $(0,0117)$ & $(0,0097)$ & $(0,0078)$ & $(0,0083)$ & $(0,0045)$ \\
\hline \multirow[t]{2}{*}{1998} & $-0,0165$ & 0,0070 & $-0,0142$ & $-0,0048$ & $-0,0074$ \\
\hline & $(0,0118)$ & $(0,0098)$ & $(0,0079)$ & $(0,0083)$ & $(0,0046)$ \\
\hline \multirow[t]{2}{*}{ idade que teve o filho } & 0,0233 & 0,0054 & $-0,0108$ & $-0,0034$ & 0,0001 \\
\hline & $(0,0052)$ & $(0,0049)$ & $(0,0054)$ & $(0,0096)$ & $(0,0023)$ \\
\hline \multirow{2}{*}{$\begin{array}{l}\text { quadrado da idade que } \\
\text { teve o filho }\end{array}$} & $-0,0002$ & 0,0000 & 0,0003 & 0,0001 & 0,0000 \\
\hline & $(0,0001)$ & $(0,0001)$ & $(0,0001)$ & $(0,0002)$ & $(0,0001)$ \\
\hline \multirow[t]{2}{*}{ anos de estudo } & 0,0356 & 0,0316 & 0,0239 & 0,0192 & 0,0239 \\
\hline & $(0,0009)$ & $(0,0007)$ & $(0,0005)$ & $(0,0006)$ & $(0,0003)$ \\
\hline $\mathrm{N}^{0}$ de observações & 26.509 & 39.649 & 58.659 & 49.940 & 174.757 \\
\hline $\begin{array}{l}\mathrm{N}^{0} \text { de observações de } \\
\text { mães de gêmeos }\end{array}$ & 171 & 240 & 299 & 211 & 921 \\
\hline Wald Chi2 (k) & $2.664,98$ & $2.787,23$ & $2.426,23$ & $1.213,5$ & $6.931,39$ \\
\hline Prob > Chi2 & 0,0000 & 0,0000 & 0,0000 & 0,0000 & 0,0000 \\
\hline Pseudo-R2 & 0,0835 & 0,0535 & 0,0302 & 0,0175 & 0,0286 \\
\hline
\end{tabular}

Observações: Efeitos marginais calculados para a mãe de características médias. Desvio padrão robusto entre parênteses. 
TABELA 46 - IMPACTO DA OCORRENNCIA DE GEMMEOS SOBRE A PROBABILIDADE DE PARTICIPAÇÃO DA MULHER NO MERCADO DE TRABALHO - TODAS AS MÃES

\begin{tabular}{|c|c|c|c|c|c|}
\hline \multirow{2}{*}{$\begin{array}{l}\text { Probabilidade de } \\
\text { participar do mercado } \\
\text { de trabalho }\end{array}$} & \multicolumn{4}{|c|}{ Considerando-se apenas mães que tiveram filhos... } & \multirow[t]{2}{*}{ Total } \\
\hline & $\begin{array}{l}\text { Há } 2 \text { anos ou menos } \\
\text { (curto-prazo) }\end{array}$ & $\begin{array}{c}\text { Entre } 3 \text { e } 6 \\
\text { anos }\end{array}$ & $\begin{array}{c}\text { Entre } 7 \text { e } 12 \\
\text { anos }\end{array}$ & $\begin{array}{c}\text { Há } 13 \text { anos ou } \\
\text { mais (longo-prazo) }\end{array}$ & \\
\hline Gêmeos & $\begin{array}{r}-0,1010 \\
(0,0349)\end{array}$ & $\begin{array}{l}-0,0267 \\
(0,0314)\end{array}$ & $\begin{array}{r}0,0131 \\
(0,0272)\end{array}$ & $\begin{array}{r}0,0007 \\
(0,0313)\end{array}$ & $\begin{array}{r}-0,0244 \\
(0,0158)\end{array}$ \\
\hline 1992 & $\begin{array}{r}-0,0641 \\
(0,0113)\end{array}$ & $\begin{array}{r}-0,0411 \\
(0,0093)\end{array}$ & $\begin{array}{r}-0,0546 \\
(0,0075)\end{array}$ & $\begin{array}{r}-0,0363 \\
(0,0079)\end{array}$ & $\begin{array}{r}-0,0534 \\
(0,0044)\end{array}$ \\
\hline 1993 & $\begin{array}{r}-0,0665 \\
(0,0112)\end{array}$ & $\begin{array}{l}-0,0605 \\
(0,0092)\end{array}$ & $\begin{array}{r}-0,0515 \\
(0,0075)\end{array}$ & $\begin{array}{r}-0,0335 \\
(0,0077)\end{array}$ & $\begin{array}{l}-0,0544 \\
(0,0043)\end{array}$ \\
\hline 1995 & $\begin{array}{r}-0,0300 \\
(0,0115)\end{array}$ & $\begin{array}{r}-0,0215 \\
(0,0093)\end{array}$ & $\begin{array}{r}-0,0241 \\
(0,0074)\end{array}$ & $\begin{array}{r}-0,0146 \\
(0,0075)\end{array}$ & $\begin{array}{l}-0,0226 \\
(0,0043)\end{array}$ \\
\hline 1996 & $\begin{array}{r}-0,0453 \\
(0,0116)\end{array}$ & $\begin{array}{r}-0,0385 \\
(0,0094)\end{array}$ & $\begin{array}{r}-0,0474 \\
(0,0075)\end{array}$ & $\begin{array}{r}-0,0323 \\
(0,0076)\end{array}$ & $\begin{array}{l}-0,0391 \\
(0,0043)\end{array}$ \\
\hline 1997 & $\begin{array}{r}-0,0372 \\
(0,0114)\end{array}$ & $\begin{array}{l}-0,0150 \\
(0,0093)\end{array}$ & $\begin{array}{l}-0,0297 \\
(0,0074)\end{array}$ & $\begin{array}{r}-0,0201 \\
(0,0075)\end{array}$ & $\begin{array}{l}-0,0245 \\
(0,0043)\end{array}$ \\
\hline 1998 & $\begin{array}{r}-0,0184 \\
(0,0115)\end{array}$ & $\begin{array}{r}0,0063 \\
(0,0093)\end{array}$ & $\begin{array}{r}-0,0134 \\
(0,0074)\end{array}$ & $\begin{array}{r}-0,0041 \\
(0,0074)\end{array}$ & $\begin{array}{l}-0,0071 \\
(0,0043)\end{array}$ \\
\hline idade que teve o filho & $\begin{array}{r}0,0249 \\
(0,0050)\end{array}$ & $\begin{array}{r}0,0048 \\
(0,0047)\end{array}$ & $\begin{array}{r}-0,0113 \\
(0,0051)\end{array}$ & $\begin{array}{r}-0,0026 \\
(0,0086)\end{array}$ & $\begin{array}{r}0,0004 \\
(0,0022)\end{array}$ \\
\hline quadrado da idade que & $-0,0002$ & 0,0001 & 0,0003 & 0,0000 & 0,0000 \\
\hline anos de estudo & $\begin{array}{r}(0,0001) \\
0,0335 \\
(0,0009) \\
\end{array}$ & $\begin{array}{r}(0,0001) \\
0,0298 \\
(0,0007) \\
\end{array}$ & $\begin{array}{r}(0,0001) \\
0,0222 \\
(0,0005)\end{array}$ & $\begin{array}{r}(0,0002) \\
0,0182 \\
(0,0005)\end{array}$ & $\begin{array}{r}(0,0001) \\
0,0220 \\
(0,0003) \\
\end{array}$ \\
\hline $\mathrm{N}^{0}$ de observações & 28.071 & 42.984 & 65.713 & 59.095 & 195.863 \\
\hline $\begin{array}{l}N^{0} \text { de observações de } \\
\text { mães de gêmeos }\end{array}$ & 187 & 274 & 329 & 242 & 1.032 \\
\hline Wald Chi2 (k) & $2.707,0$ & $2.856,2$ & $2.540,6$ & $1.354,2$ & $6.937,8$ \\
\hline Prob $>$ Chi2 & 0,0000 & 0,0000 & 0,0000 & 0,0000 & 0,0000 \\
\hline Pseudo-R2 & 0,079 & 0,050 & 0,028 & 0,017 & 0,025 \\
\hline
\end{tabular}

Observações: Efeitos marginais calculados para a mãe de características médias. Desvio padrão robusto entre parênteses.

O aumento não planejado no número de filhos parece ter um efeito negativo apenas de curto prazo (até 6 anos após o nascimento do filho). Entretanto, apenas para o período de menos de 2 anos do nascimento do filho, os parâmetros se mostraram estatisticamente significativos. Para o período de mais de 7 anos, os coeficientes, embora não estatisticamente significativos, foram positivos, indicando que o filho 'extra' aumenta a probabilidade de trabalho no longo prazo. No curto prazo, a probabilidade de participação cai 0,08 ponto porcentual se as mulheres casadas têm filhos gêmeos, isto é, a probabilidade média de ser ativa destas mulheres (considerando a mulher de características médias) passaria de $42 \%$ para $34 \%$, uma queda de $19 \%$. Quando se consideram todas as mães, a queda na probabilidade média de participação é de 0,1 ponto porcentual ou de $25 \%$ ( $44 \%$ contra $33 \%$ no caso de ter tido gêmeos). 
É interessante verificar até que ponto faz diferença trabalhar com o evento 'gêmeos' em vez de se usar diretamente o 'número de filhos'. ${ }^{14}$ No curto prazo, até 2 anos após o nascimento do primeiro filho, os impactos obtidos utilizando-se o número de filhos são bastante próximos às estimativas apresentadas nas Tabelas $4 \mathrm{a}$ e $4 \mathrm{~b}(-0,07897$ para a amostra de mães casadas e $-0,09032$ para a amostra de todas as mães). Para os outros períodos, os efeitos diminuem a partir de 7 anos após o nascimento do primeiro filho, mas continuam negativos e estatisticamente diferentes de zero (para o período de 4 a 6 anos após o nascimento do primeiro filho: $-0,08707$ e $-0,0957$; para o período de 7 a 12 anos após o nascimento do primeiro filho: $-0,03627$ e $-0,04425$; e para o período após 13 anos o nascimento do primeiro filho: $-0,00951 \mathrm{e}-0,01627) .{ }^{15}$ Pode-se pensar que no curto prazo, como o espaço entre um filho e o outro é muito pequeno, a gravidez possa até ter sido não-planejada e, por essa razão, os resultados sejam semelhantes aos encontrados quando o evento 'gêmeos' é utilizado. No entanto, quanto maior a distância do primeiro filho, um maior número de filhos deve refletir a preferência da mulher por famílias maiores, ou seja, uma maior preferência por filhos diante do trabalho. ${ }^{16}$

No caso da participação no mercado de trabalho, as dummies de anos são negativas, mostrando a tendência de crescimento da participação ao longo dos anos; para escolaridade, os coeficientes são positivos, indicando que mulheres mais educadas apresentam uma maior probabilidade de estar no mercado de trabalho. As variáveis 'idade em que teve o filho' e 'idade em teve o filho ao quadrado' mostram que inicialmente a probabilidade de participação no mercado de trabalho é crescente com a idade e depois passa a ser decrescente. Uma possibilidade é que as mulheres que postergam a gravidez são aquelas melhor inseridas no mercado de trabalho (por isso mesmo, postergam a gravidez) e, assim, quando têm seus filhos não necessariamente saem do mercado de mercado. No entanto, quanto maior for essa idade, mais difícil tende a ser a gravidez, e com maiores possibilidades a mulher se ausentaria do mercado de trabalho. Note, entretanto, que os coeficientes associados a essas variáveis são estatisticamente diferentes de zero apenas nos prazos de 0 a 2 anos e de 7 a 12 anos após o

14 Este exercício foi sugerido pelo parecerista deste artigo, com o objetivo de motivar a utilização do evento 'gêmeos'. Como a idéia é apenas de motivação, este exercício foi realizado apenas para 'participação no mercado de trabalho'.

15 Esses são os efeitos marginais da variável 'número de filhos' para uma mãe de características médias. As regressões incluem apenas mulheres com filhos, de modo a tornar os resultados comparáveis aos apresentados no trabalho. Os controles utilizados são: idade que teve o filho, idade que teve o filho ao quadrado, anos de estudo, dummies para os anos da PNAD, dummy para raça, dummies para macrorregiões e dummy para região metropolitana.

16 Scorzafave e Menezes-Filho (2001) também calcularam o impacto do número de filhos sobre a participação da mulher no mercado de trabalho. Os autores estimaram um probit, onde incluíram além dos controles observáveis tradicionais, quatro dummies para controlar a estrutura etária dos filhos: presença de filhos de 0 a 2 anos; de 3 a 5 anos; de 6 a 10 anos; e de 11 a 17 anos. $\mathrm{O}$ grupo de comparação, portanto, inclui quem não tem filhos ou quem tem filhos com mais de 17 anos. Os efeitos marginais, estimados para o ano de 1997, para cada uma das dummies, foram respectivamente: $-0,124 ;-0,044$; $-0,014$ e 0,016 . Note que o mesmo tipo de movimento é observado, ou seja, o impacto é forte no início, mas tende a se dissipar com o tempo. 
nascimento da criança, independentemente de se a amostra é a das mães casadas ou a que inclui todas as mães.

E qual o impacto desta saída do mercado de trabalho sobre o comportamento da mulher no mercado de trabalho, em termos de jornada e salário? As Tabelas $5 \mathrm{a}$ e $5 \mathrm{~b}$ apresentam as estimativas para a jornada de trabalho, obtidas por Mínimos Quadrados Ordinários, respectivamente, para a amostra de mães casadas e para a amostra que inclui todas as mães. As Tabelas $6 a$ e $6 \mathrm{~b}$, de forma análoga, apresentam os resultados obtidos para o salário-hora.

TABELA 5a - IMPACTO DA OCORRÊNCIA DE GÊMEOS SOBRE A JORNADA DE TRABALHO - MÍNIMOS QUADRADOS ORDINÁRIOS APENAS AS MÃES CASADAS

\begin{tabular}{|c|c|c|c|c|c|}
\hline \multirow{2}{*}{$\begin{array}{l}\text { Logaritmo da Jornada } \\
\text { de Trabalho }\end{array}$} & \multicolumn{4}{|c|}{ Considerando-se apenas mães que tiveram filhos... } & \multirow[t]{2}{*}{ Total } \\
\hline & $\begin{array}{l}\text { Há } 2 \text { anos ou } \\
\text { menos } \\
\text { (curto-prazo) }\end{array}$ & $\begin{array}{l}\text { Entre } 3 \text { e } 6 \\
\text { anos }\end{array}$ & $\begin{array}{l}\text { Entre } 7 \text { e } 12 \\
\text { anos }\end{array}$ & $\begin{array}{c}\text { Há } 13 \text { anos ou } \\
\text { mais (longo- } \\
\text { prazo) }\end{array}$ & \\
\hline Gêmeos & $\begin{array}{r}0,1107 \\
(0,0501)\end{array}$ & $\begin{array}{r}-0,0438 \\
(0,0706)\end{array}$ & $\begin{array}{r}0,0393 \\
(0,0411)\end{array}$ & $\begin{array}{r}-0,0192 \\
(0,0615)\end{array}$ & $\begin{array}{r}0,0154 \\
(0,0284)\end{array}$ \\
\hline 1992 & $\begin{array}{r}-0,0587 \\
(0,0228)\end{array}$ & $\begin{array}{r}-0,0721 \\
(0,0187)\end{array}$ & $\begin{array}{r}-0,0333 \\
(0,0143)\end{array}$ & $\begin{array}{r}-0,0556 \\
(0,0150)\end{array}$ & $\begin{array}{r}-0,0532 \\
(0,0084)\end{array}$ \\
\hline 1993 & $\begin{array}{r}-0,0786 \\
(0,0234)\end{array}$ & $\begin{array}{r}-0,0466 \\
(0,0184)\end{array}$ & $\begin{array}{r}-0,0406 \\
(0,0143)\end{array}$ & $\begin{array}{r}-0,0422 \\
(0,0146)\end{array}$ & $\begin{array}{l}-0,0477 \\
(0,0084)\end{array}$ \\
\hline 1995 & $\begin{array}{r}-0,0445 \\
(0,0227)\end{array}$ & $\begin{array}{r}-0,0270 \\
(0,0176)\end{array}$ & $\begin{array}{r}-0,0030 \\
(0,0137)\end{array}$ & $\begin{array}{r}-0,0286 \\
(0,0141)\end{array}$ & $\begin{array}{r}-0,0214 \\
(0,0080)\end{array}$ \\
\hline 1996 & $\begin{array}{r}-0,0257 \\
(0,0227)\end{array}$ & $\begin{array}{r}0,0060 \\
(0,0183)\end{array}$ & $\begin{array}{r}-0,0140 \\
(0,0145)\end{array}$ & $\begin{array}{r}0,0260 \\
(0,0138)\end{array}$ & $\begin{array}{r}0,0027 \\
(0,0082)\end{array}$ \\
\hline 1997 & $\begin{array}{r}-0,0097 \\
(0,0228)\end{array}$ & $\begin{array}{r}-0,0212 \\
(0,0181)\end{array}$ & $\begin{array}{r}0,0276 \\
(0,0138)\end{array}$ & $\begin{array}{r}-0,0015 \\
(0,0138)\end{array}$ & $\begin{array}{r}0,0041 \\
(0,0081)\end{array}$ \\
\hline 1998 & $\begin{array}{r}0,0110 \\
(0,0219)\end{array}$ & $\begin{array}{r}0,0184 \\
(0,0181)\end{array}$ & $\begin{array}{r}0,0184 \\
(0,0141)\end{array}$ & $\begin{array}{r}0,0109 \\
(0,0138)\end{array}$ & $\begin{array}{r}0,0154 \\
(0,0081)\end{array}$ \\
\hline idade que teve o filho & $\begin{array}{r}0,0292 \\
(0,0111)\end{array}$ & $\begin{array}{r}0,0043 \\
(0,0097)\end{array}$ & $\begin{array}{r}0,0046 \\
(0,0100)\end{array}$ & $\begin{array}{r}-0,0308 \\
(0,0162)\end{array}$ & $\begin{array}{r}-0,0143 \\
(0,0040)\end{array}$ \\
\hline $\begin{array}{l}\text { quadrado da idade que } \\
\text { teve o filho }\end{array}$ & $-0,0004$ & 0,0000 & $-0,0001$ & 0,0006 & 0,0003 \\
\hline & $(0,0002)$ & $(0,0002)$ & $(0,0002)$ & $(0,0004)$ & $(0,0001)$ \\
\hline anos de estudo & $\begin{array}{r}0,0069 \\
(0,0018)\end{array}$ & $\begin{array}{r}0,0145 \\
(0,0013)\end{array}$ & $\begin{array}{r}0,0128 \\
(0,0009)\end{array}$ & $\begin{array}{r}0,0131 \\
(0,0009)\end{array}$ & $\begin{array}{r}0,0123 \\
(0,0005)\end{array}$ \\
\hline Constante & $\begin{array}{r}2,9552 \\
(0,1467)\end{array}$ & $\begin{array}{r}3,2226 \\
(0,1193)\end{array}$ & $\begin{array}{r}3,2821 \\
(0,1151)\end{array}$ & $\begin{array}{r}3,7608 \\
(0,1645)\end{array}$ & $\begin{array}{r}3,5287 \\
(0,0480)\end{array}$ \\
\hline $\mathrm{N}^{0}$ de observações & 9.616 & 16.856 & 28.392 & 27.177 & 82.041 \\
\hline $\begin{array}{l}\mathrm{N}^{0} \text { de observações de } \\
\text { mães de gêmeos }\end{array}$ & 67 & 103 & 160 & 121 & 451 \\
\hline$F(k, n-1-k)$ & 10,92 & 23,28 & 25,82 & 28,24 & 73,25 \\
\hline Prob $>F$ & 0,0000 & 0,0000 & 0,0000 & 0,0000 & 0,0000 \\
\hline R-quadrado & 0,0124 & 0,0133 & 0,0088 & 0,0097 & 0,0085 \\
\hline
\end{tabular}

Desvio padrão robusto entre parênteses. 
TABELA 5b - IMPACTO DA OCORRENNCIA DE GEMEOS SOBRE A JORNADA DE TRABALHO - MÍNIMOS QUADRADOS ORDINÁRIOS TODAS AS MÃES

\begin{tabular}{|c|c|c|c|c|c|}
\hline \multirow{2}{*}{$\begin{array}{l}\text { Logaritmo da Jornada } \\
\text { de Trabalho }\end{array}$} & \multicolumn{4}{|c|}{ Considerando-se apenas mães que tiveram filhos... } & \multirow[t]{2}{*}{ Total } \\
\hline & $\begin{array}{c}\text { Há } 2 \text { anos ou } \\
\text { menos } \\
\text { (curto-prazo) }\end{array}$ & $\begin{array}{c}\text { Entre } 3 \text { e } 6 \\
\text { anos }\end{array}$ & $\begin{array}{c}\text { Entre } 7 \text { e } 12 \\
\text { anos }\end{array}$ & $\begin{array}{c}\text { Há } 13 \text { anos ou } \\
\text { mais (longo- } \\
\text { prazo) }\end{array}$ & \\
\hline \multirow[t]{2}{*}{ gêmeos } & 0,0996 & $-0,0139$ & 0,0253 & $-0,0159$ & 0,0142 \\
\hline & $(0,0470)$ & $(0,0602)$ & $(0,0386)$ & $(0,0526)$ & $(0,0254)$ \\
\hline \multirow[t]{2}{*}{1992} & $-0,0501$ & $-0,0593$ & $-0,0267$ & $-0,0521$ & $-0,0462$ \\
\hline & $(0,0215)$ & $(0,0170)$ & $(0,0127)$ & $(0,0129)$ & $(0,0075)$ \\
\hline \multirow[t]{2}{*}{1993} & $-0,0824$ & $-0,0423$ & $-0,0376$ & $-0,0369$ & $-0,0440$ \\
\hline & $(0,0220)$ & $(0,0168)$ & $(0,0128)$ & $(0,0125)$ & $(0,0074)$ \\
\hline \multirow[t]{2}{*}{1995} & $-0,0414$ & $-0,0254$ & $-0,0020$ & $-0,0272$ & $-0,0199$ \\
\hline & $(0,0213)$ & $(0,0162)$ & $(0,0121)$ & $(0,0121)$ & $(0,0071)$ \\
\hline \multirow[t]{2}{*}{1996} & $-0,0216$ & 0,0076 & $-0,0092$ & 0,0212 & 0,0044 \\
\hline & $(0,0211)$ & $(0,0167)$ & $(0,0129)$ & $(0,0118)$ & $(0,0073)$ \\
\hline \multirow[t]{2}{*}{1997} & $-0,0153$ & $-0,0220$ & 0,0291 & $-0,0021$ & 0,0040 \\
\hline & $(0,0213)$ & $(0,0165)$ & $(0,0122)$ & $(0,0119)$ & $(0,0071)$ \\
\hline \multirow[t]{2}{*}{1998} & 0,0099 & 0,0227 & 0,0178 & 0,0135 & 0,0169 \\
\hline & $(0,0205)$ & $(0,0164)$ & $(0,0125)$ & $(0,0118)$ & $(0,0072)$ \\
\hline \multirow[t]{2}{*}{ idade que teve o filho } & 0,0266 & 0,0030 & 0,0000 & $-0,0339$ & $-0,0154$ \\
\hline & $(0,0102)$ & $(0,0088)$ & $(0,0089)$ & $(0,0138)$ & $(0,0036)$ \\
\hline \multirow{2}{*}{$\begin{array}{l}\text { quadrado da idade que } \\
\text { teve o filho }\end{array}$} & $-0,0004$ & 0,0000 & 0,0000 & 0,0007 & 0,0003 \\
\hline & $(0,0002)$ & $(0,0002)$ & $(0,0002)$ & $(0,0003)$ & $(0,0001)$ \\
\hline \multirow[t]{2}{*}{ anos de estudo } & 0,0051 & 0,0117 & 0,0096 & 0,0095 & 0,0091 \\
\hline & $(0,0017)$ & $(0,0012)$ & $(0,0008)$ & $(0,0008)$ & $(0,0005)$ \\
\hline \multirow[t]{2}{*}{ constante } & 3,0249 & 3,2832 & 3,3811 & 3,8449 & 3,5951 \\
\hline & $(0,1354)$ & $(0,1086)$ & $(0,1024)$ & $(0,1406)$ & $(0,0426)$ \\
\hline $\mathrm{N}^{0}$ de observações & 10.629 & 19.279 & 33.845 & 34.331 & 98.084 \\
\hline $\begin{array}{l}\mathrm{N}^{0} \text { de observações de } \\
\text { mães de gêmeos }\end{array}$ & 72 & 128 & 185 & 144 & 529 \\
\hline$F(k, n-1-k)$ & 9,86 & 20,06 & 20,17 & 23,01 & 55,77 \\
\hline Prob $>F$ & 0,0000 & 0,0000 & 0,0000 & 0,0000 & 0,0000 \\
\hline R-quadrado & 0,01 & 0,01 & 0,0058 & 0,0065 & 0,0055 \\
\hline
\end{tabular}

Desvio padrão robusto entre parênteses. 
TABELA 6a-IMPACTO DA OCORRÊNCIA DE GÊMEOS SOBRE O SALÁRIOHORA - MÍNIMOS QUADRADOS ORDINÁRIOS - APENAS AS MÃES CASADAS

\begin{tabular}{|c|c|c|c|c|c|}
\hline \multirow{2}{*}{$\begin{array}{l}\text { Logaritmo do } \\
\text { Salário-Hora }\end{array}$} & \multicolumn{4}{|c|}{ Considerando-se apenas mães que tiveram filhos... } & \multirow[t]{2}{*}{ Total } \\
\hline & $\begin{array}{c}\text { Há } 2 \text { anos ou } \\
\text { menos } \\
\text { (curto-prazo) }\end{array}$ & $\begin{array}{c}\text { Entre } 3 \text { e } 6 \\
\text { anos }\end{array}$ & $\begin{array}{l}\text { Entre } 7 \text { e } 12 \\
\text { anos }\end{array}$ & $\begin{array}{c}\text { Há } 13 \text { anos ou } \\
\text { mais (longo- } \\
\text { prazo) }\end{array}$ & \\
\hline \multirow[t]{2}{*}{ Gêmeos } & 0,2239 & 0,0755 & 0,0614 & $-0,0523$ & 0,0630 \\
\hline & $(0,0915)$ & $(0,0811)$ & $(0,0574)$ & $(0,0785)$ & $(0,0375)$ \\
\hline \multirow[t]{2}{*}{1992} & $-0,1620$ & $-0,1565$ & $-0,1974$ & $-0,1664$ & $-0,1790$ \\
\hline & $(0,0289)$ & $(0,0240)$ & $(0,0181)$ & $(0,0194)$ & $(0,0109)$ \\
\hline \multirow[t]{2}{*}{1993} & $-0,2957$ & $-0,2638$ & $-0,2737$ & $-0,2729$ & $-0,2768$ \\
\hline & $(0,0296)$ & $(0,0235)$ & $(0,0187)$ & $(0,0186)$ & $(0,0108)$ \\
\hline \multirow[t]{2}{*}{1995} & 0,1450 & 0,1621 & 0,0786 & 0,1392 & 0,1218 \\
\hline & $(0,0288)$ & $(0,0223)$ & $(0,0169)$ & $(0,0178)$ & $(0,0101)$ \\
\hline \multirow[t]{2}{*}{1996} & 0,1220 & 0,1536 & 0,1365 & 0,1359 & 0,1395 \\
\hline & $(0,0298)$ & $(0,0227)$ & $(0,0181)$ & $(0,0178)$ & $(0,0105)$ \\
\hline \multirow[t]{2}{*}{1997} & 0,0551 & 0,1305 & 0,0623 & 0,1298 & 0,0983 \\
\hline & $(0,0286)$ & $(0,0222)$ & $(0,0174)$ & $(0,0176)$ & $(0,0102)$ \\
\hline \multirow[t]{2}{*}{1998} & 0,0523 & 0,0934 & 0,0381 & 0,0829 & 0,0671 \\
\hline & $(0,0279)$ & $(0,0222)$ & $(0,0171)$ & $(0,0173)$ & $(0,0101)$ \\
\hline \multirow[t]{2}{*}{ idade que teve o filho } & 0,0652 & 0,0207 & 0,0036 & $-0,0262$ & 0,0039 \\
\hline & $(0,0138)$ & $(0,0119)$ & $(0,0124)$ & $(0,0211)$ & $(0,0054)$ \\
\hline \multirow{2}{*}{$\begin{array}{l}\text { quadrado da idade que } \\
\text { teve o filho }\end{array}$} & $-0,0006$ & 0,0001 & 0,0004 & 0,0010 & 0,0003 \\
\hline & $(0,0003)$ & $(0,0002)$ & $(0,0003)$ & $(0,0005)$ & $(0,0001)$ \\
\hline \multirow[t]{2}{*}{ anos de estudo } & 0,1427 & 0,1362 & 0,1331 & 0,1216 & 0,1286 \\
\hline & $(0,0023)$ & $(0,0017)$ & $(0,0012)$ & $(0,0012)$ & $(0,0007)$ \\
\hline \multirow[t]{2}{*}{ Constante } & $-0,4807$ & 0,2763 & 0,6801 & 1,1943 & 0,7519 \\
\hline & $(0,1766)$ & $(0,1431)$ & $(0,1407)$ & $(0,2143)$ & $(0,0631)$ \\
\hline $\mathrm{N}^{0}$ de observações & 8.756 & 15.133 & 25.272 & 23.977 & 73.138 \\
\hline $\begin{array}{l}\mathrm{N}^{0} \text { de observações de } \\
\text { mães de gêmeos }\end{array}$ & 65 & 95 & 145 & 108 & 413 \\
\hline$F(k, n-1-k)$ & 643,3 & 1000,14 & 1567,79 & 1169,8 & 4304,62 \\
\hline Prob $>\mathrm{F}$ & 0,0000 & 0,0000 & 0,0000 & 0,0000 & 0,0000 \\
\hline R-quadrado & 0,4498 & 0,4116 & 0,3957 & 0,3388 & 0,3816 \\
\hline
\end{tabular}

Desvio padrão robusto entre parênteses. 
TABELA 66 - IMPACTO DA OCORRÊNCIA DE GÊMEOS SOBRE O SALÁRIOHORA - MÍNIMOS QUADRADOS ORDINÁRIOS - TODAS AS MÃES

\begin{tabular}{|c|c|c|c|c|c|}
\hline \multirow{2}{*}{$\begin{array}{l}\text { Logaritmo do } \\
\text { Salário-Hora }\end{array}$} & \multicolumn{4}{|c|}{ Considerando-se apenas mães que tiveram filhos... } & \multirow[t]{2}{*}{ Total } \\
\hline & $\begin{array}{l}\text { Há } 2 \text { anos ou menos } \\
\text { (curto-prazo) }\end{array}$ & $\begin{array}{l}\text { Entre } 3 \text { e } 6 \\
\text { anos }\end{array}$ & $\begin{array}{c}\text { Entre } 7 \text { e } 12 \\
\text { anos }\end{array}$ & $\begin{array}{l}\text { Há } 13 \text { anos ou mais } \\
\text { (longo-prazo) }\end{array}$ & \\
\hline \multirow[t]{2}{*}{ Gêmeos } & 0,1967 & 0,0524 & 0,0762 & $-0,0622$ & 0,0488 \\
\hline & $(0,0874)$ & $(0,0701)$ & $(0,0539)$ & $(0,0687)$ & $(0,0339)$ \\
\hline 1992 & $\begin{array}{c}-0,1672 \\
(0,0276)\end{array}$ & $\begin{array}{c}-0,1621 \\
(0,0222)\end{array}$ & $\begin{array}{r}-0,2050 \\
(0,0164)\end{array}$ & $\begin{array}{r}-0,1478 \\
(0,0169)\end{array}$ & $\begin{array}{r}-0,1781 \\
(0,0098)\end{array}$ \\
\hline 1993 & $\begin{array}{l}-0,2957 \\
(0,0284)\end{array}$ & $\begin{array}{r}-0,2670 \\
(0,0219)\end{array}$ & $\begin{array}{r}-0,2719 \\
(0,0169)\end{array}$ & $\begin{array}{r}-0,2540 \\
(0,0163)\end{array}$ & $\begin{array}{r}-0,2700 \\
(0,0098)\end{array}$ \\
\hline 1995 & $\begin{array}{r}0,1343 \\
(0,0273)\end{array}$ & $\begin{array}{r}0,1602 \\
(0,0207)\end{array}$ & $\begin{array}{r}0,0793 \\
(0,0153)\end{array}$ & $\begin{array}{r}0,1501 \\
(0,0156)\end{array}$ & $\begin{array}{r}0,1241 \\
(0,0092)\end{array}$ \\
\hline 1996 & $\begin{array}{r}0,1255 \\
(0,0282)\end{array}$ & $\begin{array}{r}0,1554 \\
(0,0211)\end{array}$ & $\begin{array}{r}0,1231 \\
(0,0163)\end{array}$ & $\begin{array}{r}0,1403 \\
(0,0156)\end{array}$ & $\begin{array}{r}0,1373 \\
(0,0095)\end{array}$ \\
\hline 1997 & $\begin{array}{r}0,0548 \\
(0,0269)\end{array}$ & $\begin{array}{r}0,1406 \\
(0,0204)\end{array}$ & $\begin{array}{r}0,0615 \\
(0,0156)\end{array}$ & $\begin{array}{r}0,1289 \\
(0,0152)\end{array}$ & $\begin{array}{r}0,1004 \\
(0,0091)\end{array}$ \\
\hline 1998 & $\begin{array}{r}0,0511 \\
(0,0264)\end{array}$ & $\begin{array}{r}0,0884 \\
(0,0205)\end{array}$ & $\begin{array}{r}0,0346 \\
(0,0154)\end{array}$ & $\begin{array}{r}0,0950 \\
(0,0150)\end{array}$ & $\begin{array}{r}0,0693 \\
(0,0090)\end{array}$ \\
\hline idade que teve o filho & $\begin{array}{r}0,0576 \\
(0,0127)\end{array}$ & $\begin{array}{r}0,0235 \\
(0,0110)\end{array}$ & $\begin{array}{r}0,0051 \\
(0,0112)\end{array}$ & $\begin{array}{r}-0,0171 \\
(0,0184)\end{array}$ & $\begin{array}{r}0,0002 \\
(0,0049)\end{array}$ \\
\hline \multirow{2}{*}{$\begin{array}{l}\text { quadrado da idade que } \\
\text { teve o filho }\end{array}$} & $-0,0005$ & 0,0000 & 0,0003 & 0,0007 & 0,0003 \\
\hline & $(0,0002)$ & $(0,0002)$ & $(0,0002)$ & $(0,0004)$ & $(0,0001)$ \\
\hline anos de estudo & $\begin{array}{r}0,1436 \\
(0,0021)\end{array}$ & $\begin{array}{r}0,1376 \\
(0,0015)\end{array}$ & $\begin{array}{r}0,1345 \\
(0,0011)\end{array}$ & $\begin{array}{r}0,1225 \\
(0,0011)\end{array}$ & $\begin{array}{r}0,1296 \\
(0,0007)\end{array}$ \\
\hline Constante & $\begin{array}{r}-0,3953 \\
(0,1637)\end{array}$ & $\begin{array}{r}0,2249 \\
(0,1329)\end{array}$ & $\begin{array}{r}0,6520 \\
(0,1272)\end{array}$ & $\begin{array}{r}1,1053 \\
(0,1868)\end{array}$ & $\begin{array}{r}0,7938 \\
(0,0571) \\
\end{array}$ \\
\hline $\mathrm{N}^{0}$ de observações & 9760 & 17522 & 30637 & 30994 & 88913 \\
\hline $\begin{array}{l}\mathrm{N}^{0} \text { de observações de } \\
\text { mães de gêmeos }\end{array}$ & 70 & 119 & 170 & 131 & 490 \\
\hline$F(k, n-1-k)$ & 741,34 & 1163,76 & 1942,72 & 1497,87 & 5244,55 \\
\hline Prob $>F$ & 0,0000 & 0,0000 & 0,0000 & 0,0000 & 0,0000 \\
\hline R-quadrado & 0,4568 & 0,4169 & 0,4032 & 0,3398 & 0,3843 \\
\hline
\end{tabular}

Desvio padrão robusto entre parênteses.

Como é possível observar, no curto prazo (até 2 anos depois do nascimento da criança) as mães de gêmeos tanto trabalham mais (11,7\%: mães casadas e 10,5\%: todas as mães) como ganham mais (25,1\%: mães casadas e $21,7 \%$ : todas as mães ) do que as mães de não-gêmeos. ${ }^{17}$ Este resultado pode estar indicando a existência de um possível viés de seleção. Na tabela anterior foi visto que as mães de gêmeos saem momentaneamente do mercado de trabalho após o nascimento do filho. Se as mães de gêmeos que permanecem no mercado têm maior salário-hora relativamente às mães de não-gêmeos

17 Como as variáveis dependentes são os logaritmos das variáveis de interesse, o coeficiente associado à dummy gêmeos corresponde, aproximadamente, ao diferencial dos logaritmos de jornadas ou de salários entre mães de gêmeos e mães de não-gêmeos. Portanto, o exponencial do coeficiente associado à dummy gêmeos é justamente a razão das jornadas ou dos salários entre mães de gêmeos e mães de não-gêmeos. 
que ficam, é provável que as mães de gêmeos que continuarem no mercado sejam 'melhores' em atributos não-observáveis do que as de não-gêmeos. Uma evidência a favor deste possível viés está no fato deste diferencial de salário desaparecer no longo prazo, momento em que os efeitos negativos do choque diminuem e as mães estão retornando ao mercado de trabalho. Para ver se isto é verdade optou-se por reestimar as equações acima via Heckman, método estatístico que corrige problemas de seleção na amostra. As Tabelas $7 \mathrm{a}$ e $7 \mathrm{~b}$ apresentam os resultados obtidos para a jornada de trabalho e as tabelas 8 a e 8 b os resultados para o salário-hora.

TABELA 7a-IMPACTO DA OCORR ENNCIA DE GEMEOS SOBRE A JORNADA DE TRABALHO - PROCEDIMENTO DE HECKMAN - APENAS AS MÃES CASADAS

\begin{tabular}{|c|c|c|c|c|c|}
\hline \multirow{2}{*}{$\begin{array}{l}\text { Logaritmo da Jornada } \\
\text { de Trabalho }\end{array}$} & \multicolumn{4}{|c|}{ Considerando-se apenas mães que tiveram filhos... } & \multirow[t]{2}{*}{ Total } \\
\hline & $\begin{array}{l}\text { Há } 2 \text { anos ou menos } \\
\text { (curto-prazo) }\end{array}$ & $\begin{array}{l}\text { Entre } 3 \text { e } 6 \\
\text { anos }\end{array}$ & $\begin{array}{l}\text { Entre } 7 \text { e } 12 \\
\text { anos }\end{array}$ & $\begin{array}{l}\text { Há } 13 \text { anos ou } \\
\text { mais (longo-prazo) }\end{array}$ & \\
\hline \multicolumn{6}{|l|}{ Equação Principal } \\
\hline Gêmeos & $\begin{array}{r}0,1653 \\
(0,0970)\end{array}$ & $\begin{array}{r}-0,0383 \\
(0,0666)\end{array}$ & $\begin{array}{r}0,0253 \\
(0,0523)\end{array}$ & $\begin{array}{r}-0,0112 \\
(0,0581)\end{array}$ & $\begin{array}{r}0,0127 \\
(0,0313)\end{array}$ \\
\hline 1992 & $\begin{array}{r}-0,0390 \\
(0,0298)\end{array}$ & $\begin{array}{r}-0,0682 \\
(0,0197)\end{array}$ & $\begin{array}{r}-0,0232 \\
(0,0153)\end{array}$ & $\begin{array}{r}-0,0580 \\
(0,0148)\end{array}$ & $\begin{array}{l}-0,0439 \\
(0,0094)\end{array}$ \\
\hline 1993 & $\begin{array}{r}-0,0557 \\
(0,0300)\end{array}$ & $\begin{array}{r}-0,0362 \\
(0,0199)\end{array}$ & $\begin{array}{r}-0,0352 \\
(0,0148)\end{array}$ & $\begin{array}{l}-0,0416 \\
(0,0146)\end{array}$ & $\begin{array}{l}-0,0395 \\
(0,0091)\end{array}$ \\
\hline 1995 & $\begin{array}{r}-0,0673 \\
(0,0296)\end{array}$ & $\begin{array}{r}-0,0372 \\
(0,0200)\end{array}$ & $\begin{array}{r}-0,0069 \\
(0,0144)\end{array}$ & $\begin{array}{l}-0,0311 \\
(0,0142)\end{array}$ & $\begin{array}{l}-0,0291 \\
(0,0089)\end{array}$ \\
\hline 1996 & $\begin{array}{r}-0,0203 \\
(0,0298)\end{array}$ & $\begin{array}{r}0,0087 \\
(0,0199)\end{array}$ & $\begin{array}{r}-0,0018 \\
(0,0152)\end{array}$ & $\begin{array}{r}0,0276 \\
(0,0143)\end{array}$ & $\begin{array}{r}0,0091 \\
(0,0088)\end{array}$ \\
\hline 1997 & $\begin{array}{r}0,0154 \\
(0,0301)\end{array}$ & $\begin{array}{r}-0,0220 \\
(0,0195)\end{array}$ & $\begin{array}{r}0,0331 \\
(0,0144)\end{array}$ & $\begin{array}{l}-0,0057 \\
(0,0141)\end{array}$ & $\begin{array}{r}0,0061 \\
(0,0086)\end{array}$ \\
\hline 1998 & $\begin{array}{r}0,0267 \\
(0,0299)\end{array}$ & $\begin{array}{r}0,0111 \\
(0,0195)\end{array}$ & $\begin{array}{r}0,0235 \\
(0,0146)\end{array}$ & $\begin{array}{r}0,0122 \\
(0,0141)\end{array}$ & $\begin{array}{r}0,0166 \\
(0,0086)\end{array}$ \\
\hline região Metropolitana & $\begin{array}{r}0,1676 \\
(0,0209)\end{array}$ & $\begin{array}{r}0,1307 \\
(0,0149)\end{array}$ & $\begin{array}{r}0,1149 \\
(0,0123)\end{array}$ & $\begin{array}{r}0,0947 \\
(0,0093)\end{array}$ & $\begin{array}{r}0,1216 \\
(0,0090)\end{array}$ \\
\hline região Norte & $\begin{array}{r}-0,0982 \\
(0,0382)\end{array}$ & $\begin{array}{r}-0,0389 \\
(0,0248)\end{array}$ & $\begin{array}{r}-0,0154 \\
(0,0183)\end{array}$ & $\begin{array}{r}-0,0410 \\
(0,0172)\end{array}$ & $\begin{array}{l}-0,0417 \\
(0,0111)\end{array}$ \\
\hline região Nordeste & $\begin{array}{r}-0,1512 \\
(0,0307)\end{array}$ & $\begin{array}{r}-0,0548 \\
(0,0192)\end{array}$ & $\begin{array}{r}-0,0769 \\
(0,0149)\end{array}$ & $\begin{array}{l}-0,0736 \\
(0,0139)\end{array}$ & $\begin{array}{l}-0,0775 \\
(0,0089)\end{array}$ \\
\hline região Sudeste & $\begin{array}{r}-0,1144 \\
(0,0272)\end{array}$ & $\begin{array}{r}-0,0320 \\
(0,0182)\end{array}$ & $\begin{array}{r}-0,0374 \\
(0,0137)\end{array}$ & $\begin{array}{r}-0,0325 \\
(0,0132)\end{array}$ & $\begin{array}{l}-0,0441 \\
(0,0080)\end{array}$ \\
\hline região Sul & $\begin{array}{r}-0,2291 \\
(0,0449)\end{array}$ & $\begin{array}{r}-0,1006 \\
(0,0320)\end{array}$ & $\begin{array}{r}-0,0820 \\
(0,0207)\end{array}$ & $\begin{array}{r}-0,0624 \\
(0,0161)\end{array}$ & $\begin{array}{l}-0,1001 \\
(0,0175)\end{array}$ \\
\hline Branca & $\begin{array}{r}0,0870 \\
(0,0212)\end{array}$ & $\begin{array}{r}0,0233 \\
(0,0130)\end{array}$ & $\begin{array}{r}0,0227 \\
(0,0099)\end{array}$ & $\begin{array}{r}0,0142 \\
(0,0098)\end{array}$ & $\begin{array}{r}0,0296 \\
(0,0070)\end{array}$ \\
\hline anos de estudo & $\begin{array}{r}-0,0510 \\
(0,0132)\end{array}$ & $\begin{array}{r}-0,0079 \\
(0,0082)\end{array}$ & $\begin{array}{r}0,0017 \\
(0,0045)\end{array}$ & $\begin{array}{r}0,0109 \\
(0,0024)\end{array}$ & $\begin{array}{l}-0,0021 \\
(0,0044)\end{array}$ \\
\hline idade que teve o filho & $\begin{array}{r}-0,0446 \\
(0,0214)\end{array}$ & $\begin{array}{r}-0,0142 \\
(0,0113)\end{array}$ & $\begin{array}{r}0,0059 \\
(0,0100)\end{array}$ & $\begin{array}{r}-0,0261 \\
(0,0166)\end{array}$ & $\begin{array}{l}-0,0176 \\
(0,0046)\end{array}$ \\
\hline \multirow[t]{2}{*}{$\begin{array}{l}\text { quadrado da idade que teve } \\
\text { o filho }\end{array}$} & 0,0005 & 0,0002 & $-0,0002$ & 0,0005 & 0,0003 \\
\hline & $(0,0003)$ & $(0,0002)$ & $(0,0002)$ & $(0,0004)$ & $(0,0001)$ \\
\hline Constante & 5,5886 & 4,0692 & 3,5632 & 3,7504 & 3,9658 \\
\hline
\end{tabular}




\begin{tabular}{|c|c|c|c|c|c|}
\hline \multirow{2}{*}{$\begin{array}{l}\text { Logaritmo da Jornada } \\
\text { de Trabalho }\end{array}$} & \multicolumn{4}{|c|}{ Considerando-se apenas mães que tiveram filhos... } & \multirow[t]{2}{*}{ Total } \\
\hline & $\begin{array}{l}\text { Há } 2 \text { anos ou menos } \\
\text { (curto-prazo) }\end{array}$ & $\begin{array}{l}\text { Entre } 3 \text { e } 6 \\
\text { anos }\end{array}$ & $\begin{array}{l}\text { Entre } 7 \text { e } 12 \\
\text { anos }\end{array}$ & $\begin{array}{l}\text { Há } 13 \text { anos ou } \\
\text { mais (longo-prazo) }\end{array}$ & \\
\hline & $(0,6251)$ & $(0,3179)$ & $(0,1694)$ & $(0,1824)$ & $(0,1527)$ \\
\hline \multicolumn{6}{|l|}{ Equação de Seleção } \\
\hline Gêmeos & $\begin{array}{r}-0,1142 \\
(0,1017)\end{array}$ & $\begin{array}{l}-0,0237 \\
(0,0843)\end{array}$ & $\begin{array}{r}0,0792 \\
(0,0749)\end{array}$ & $\begin{array}{r}0,0725 \\
(0,0891)\end{array}$ & $\begin{array}{r}0,0077 \\
(0,0423)\end{array}$ \\
\hline 1992 & $\begin{array}{r}-0,0369 \\
(0,0308)\end{array}$ & $\begin{array}{r}-0,0125 \\
(0,0246)\end{array}$ & $\begin{array}{r}-0,0588 \\
(0,0199)\end{array}$ & $\begin{array}{r}-0,0125 \\
(0,0219)\end{array}$ & $\begin{array}{l}-0,0467 \\
(0,0115)\end{array}$ \\
\hline 1993 & $\begin{array}{r}-0,0404 \\
(0,0309)\end{array}$ & $\begin{array}{r}-0,0382 \\
(0,0243)\end{array}$ & $\begin{array}{r}-0,0362 \\
(0,0199)\end{array}$ & $\begin{array}{r}0,0060 \\
(0,0216)\end{array}$ & $\begin{array}{l}-0,0369 \\
(0,0115)\end{array}$ \\
\hline 1995 & $\begin{array}{r}0,0376 \\
(0,0309)\end{array}$ & $\begin{array}{r}0,0544 \\
(0,0245)\end{array}$ & $\begin{array}{r}0,0410 \\
(0,0197)\end{array}$ & $\begin{array}{r}0,0612 \\
(0,0212)\end{array}$ & $\begin{array}{r}0,0405 \\
(0,0114)\end{array}$ \\
\hline 1996 & $\begin{array}{r}-0,0025 \\
(0,0315)\end{array}$ & $\begin{array}{l}-0,0117 \\
(0,0248)\end{array}$ & $\begin{array}{r}-0,0536 \\
(0,0200)\end{array}$ & $\begin{array}{r}0,0024 \\
(0,0213)\end{array}$ & $\begin{array}{l}-0,0210 \\
(0,0115)\end{array}$ \\
\hline 1997 & $\begin{array}{r}-0,0400 \\
(0,0311)\end{array}$ & $\begin{array}{r}0,0223 \\
(0,0245)\end{array}$ & $\begin{array}{r}-0,0197 \\
(0,0197)\end{array}$ & $\begin{array}{r}0,0095 \\
(0,0211)\end{array}$ & $\begin{array}{l}-0,0073 \\
(0,0114)\end{array}$ \\
\hline 1998 & $\begin{array}{r}-0,0332 \\
(0,0312)\end{array}$ & $\begin{array}{r}0,0225 \\
(0,0245)\end{array}$ & $\begin{array}{r}-0,0303 \\
(0,0198)\end{array}$ & $\begin{array}{r}0,0222 \\
(0,0212)\end{array}$ & $\begin{array}{l}-0,0060 \\
(0,0114)\end{array}$ \\
\hline região Metropolitana & $\begin{array}{r}-0,0926 \\
(0,0172)\end{array}$ & $\begin{array}{l}-0,0997 \\
(0,0136)\end{array}$ & $\begin{array}{r}-0,1333 \\
(0,0110)\end{array}$ & $\begin{array}{r}-0,1076 \\
(0,0120)\end{array}$ & $\begin{array}{r}-0,1070 \\
(0,0064)\end{array}$ \\
\hline região Norte & $\begin{array}{r}0,0372 \\
(0,0390)\end{array}$ & $\begin{array}{l}-0,0186 \\
(0,0304)\end{array}$ & $\begin{array}{r}0,0612 \\
(0,0243)\end{array}$ & $\begin{array}{r}0,0413 \\
(0,0258)\end{array}$ & $\begin{array}{r}0,0470 \\
(0,0140)\end{array}$ \\
\hline região Nordeste & $\begin{array}{r}0,0877 \\
(0,0294)\end{array}$ & $\begin{array}{r}0,0297 \\
(0,0235)\end{array}$ & $\begin{array}{r}0,0684 \\
(0,0192)\end{array}$ & $\begin{array}{r}0,0001 \\
(0,0208)\end{array}$ & $\begin{array}{r}0,0408 \\
(0,0110)\end{array}$ \\
\hline região Sudeste & $\begin{array}{r}0,0087 \\
(0,0283)\end{array}$ & $\begin{array}{r}-0,0259 \\
(0,0224)\end{array}$ & $\begin{array}{r}-0,0336 \\
(0,0182)\end{array}$ & $\begin{array}{r}-0,0286 \\
(0,0196)\end{array}$ & $\begin{array}{r}-0,0074 \\
(0,0105)\end{array}$ \\
\hline região Sul & $\begin{array}{r}0,2442 \\
(0,0314)\end{array}$ & $\begin{array}{r}0,2533 \\
(0,0250)\end{array}$ & $\begin{array}{r}0,2149 \\
(0,0204)\end{array}$ & $\begin{array}{r}0,1677 \\
(0,0220)\end{array}$ & $\begin{array}{r}0,2184 \\
(0,0117)\end{array}$ \\
\hline Branca & $\begin{array}{r}0,0960 \\
(0,0026)\end{array}$ & $\begin{array}{r}0,0834 \\
(0,0019)\end{array}$ & $\begin{array}{r}0,0675 \\
(0,0015)\end{array}$ & $\begin{array}{r}0,0626 \\
(0,0017)\end{array}$ & $\begin{array}{r}0,0639 \\
(0,0009)\end{array}$ \\
\hline anos de estudo & $\begin{array}{r}-0,0677 \\
(0,0189)\end{array}$ & $\begin{array}{r}-0,0443 \\
(0,0149)\end{array}$ & $\begin{array}{l}-0,0577 \\
(0,0121)\end{array}$ & $\begin{array}{r}-0,0875 \\
(0,0130)\end{array}$ & $\begin{array}{r}-0,0611 \\
(0,0070)\end{array}$ \\
\hline idade que teve o filho & $\begin{array}{r}0,0912 \\
(0,0135)\end{array}$ & $\begin{array}{r}0,0355 \\
(0,0125)\end{array}$ & $\begin{array}{r}-0,0115 \\
(0,0137)\end{array}$ & $\begin{array}{r}-0,0035 \\
(0,0248)\end{array}$ & $\begin{array}{r}0,0141 \\
(0,0059)\end{array}$ \\
\hline \multirow[t]{2}{*}{$\begin{array}{l}\text { quadrado da idade que teve } \\
\text { o filho }\end{array}$} & $-0,0009$ & $-0,0002$ & 0,0006 & 0,0002 & $-0,0001$ \\
\hline & $(0,0003)$ & $(0,0003)$ & $(0,0003)$ & $(0,0006)$ & $(0,0001)$ \\
\hline renda do não trabalho & $\begin{array}{r}-0,000025 \\
(0,000008)\end{array}$ & $\begin{array}{r}-0,000028 \\
(0,000006)\end{array}$ & $\begin{array}{l}-0,000027 \\
(0,000004)\end{array}$ & $\begin{array}{l}-0,000080 \\
(0,000005)\end{array}$ & $\begin{array}{l}-0,000018 \\
(0,000003)\end{array}$ \\
\hline Constante & $\begin{array}{r}-2,7064 \\
(0,1685)\end{array}$ & $\begin{array}{l}-1,4873 \\
(0,1482) \\
\end{array}$ & $\begin{array}{r}-0,4785 \\
(0,1543)\end{array}$ & $\begin{array}{r}-0,1488 \\
(0,2522)\end{array}$ & $\begin{array}{r}-0,7404 \\
(0,0694)\end{array}$ \\
\hline \multirow[t]{2}{*}{ Razão inversa de Mills } & $-0,9090$ & $-0,4220$ & $-0,2497$ & $-0,0337$ & $-0,3359$ \\
\hline & $(0,2102)$ & $(0,1556)$ & $(0,1086)$ & $(0,0687)$ & $(0,1101)$ \\
\hline número de observações & 26.036 & 39.006 & 57.451 & 48.698 & 171.191 \\
\hline Censuradas & 16.669 & 22.509 & 29.772 & 22.300 & 91.250 \\
\hline não censuradas & 9.367 & 16.497 & 27.679 & 26.398 & 79.941 \\
\hline $\begin{array}{l}n^{0} \text { de obs. de mães de } \\
\text { gêmeos não-censuradas }\end{array}$ & 66 & 103 & 158 & 118 & 445 \\
\hline Wald chi2 $(\mathrm{k})$ & $3.020,51$ & $3.180,12$ & $3.175,57$ & $1.960,67$ & $8.096,43$ \\
\hline Prob > chi2 & 0,0000 & 0,0000 & 0,0000 & 0,0000 & 0,0000 \\
\hline
\end{tabular}

Desvio padrão robusto entre parênteses. 
TABELA 7b - IMPACTO DA OCORRENNCIA DE GEMEOS SOBRE A JORNADA DE TRABALHO - PROCEDIMENTO DE HECKMAN - TODAS AS $M \tilde{A E S}$

\begin{tabular}{|c|c|c|c|c|c|}
\hline \multirow{2}{*}{$\begin{array}{l}\text { Logaritmo da Jornada } \\
\text { de Trabalho }\end{array}$} & \multicolumn{4}{|c|}{ Considerando-se apenas mães que tiveram filhos... } & \multirow[t]{2}{*}{ Total } \\
\hline & $\begin{array}{l}\text { Há } 2 \text { anos ou menos } \\
\text { (curto-prazo) }\end{array}$ & $\begin{array}{l}\text { Entre } 3 \text { e } 6 \\
\text { anos }\end{array}$ & $\begin{array}{l}\text { Entre } 7 \text { e } 12 \\
\text { anos }\end{array}$ & $\begin{array}{l}\text { Há } 13 \text { anos ou } \\
\text { mais (longo-prazo) }\end{array}$ & \\
\hline \multicolumn{6}{|l|}{ Equação Principal } \\
\hline \multirow[t]{2}{*}{ Gêmeos } & 0,1601 & $-0,0222$ & 0,0164 & $-0,0124$ & 0,0131 \\
\hline & $(0,0838)$ & $(0,0575)$ & $(0,0463)$ & $(0,0518)$ & $(0,0275)$ \\
\hline \multirow[t]{2}{*}{1992} & $-0,0360$ & $-0,0579$ & $-0,0198$ & $-0,0541$ & $-0,0399$ \\
\hline & $(0,0253)$ & $(0,0175)$ & $(0,0129)$ & $(0,0128)$ & $(0,0077)$ \\
\hline \multirow[t]{2}{*}{1993} & $-0,0613$ & $-0,0332$ & $-0,0335$ & $-0,0359$ & $-0,0370$ \\
\hline & $(0,0255)$ & $(0,0176)$ & $(0,0128)$ & $(0,0126)$ & $(0,0076)$ \\
\hline \multirow[t]{2}{*}{1995} & $-0,0592$ & $-0,0303$ & $-0,0042$ & $-0,0331$ & $-0,0246$ \\
\hline & $(0,0251)$ & $(0,0175)$ & $(0,0125)$ & $(0,0123)$ & $(0,0074)$ \\
\hline \multirow[t]{2}{*}{1996} & $-0,0141$ & 0,0104 & $-0,0003$ & 0,0240 & 0,0099 \\
\hline & $(0,0254)$ & $(0,0177)$ & $(0,0129)$ & $(0,0123)$ & $(0,0076)$ \\
\hline \multirow[t]{2}{*}{1997} & 0,0013 & $-0,0221$ & 0,0329 & $-0,0035$ & 0,0060 \\
\hline & $(0,0253)$ & $(0,0174)$ & $(0,0125)$ & $(0,0122)$ & $(0,0074)$ \\
\hline \multirow[t]{2}{*}{1998} & 0,0198 & 0,0186 & 0,0225 & 0,0132 & 0,0184 \\
\hline & $(0,0252)$ & $(0,0174)$ & $(0,0126)$ & $(0,0121)$ & $(0,0074)$ \\
\hline \multirow[t]{2}{*}{ região Metropolitana } & 0,1456 & 0,1176 & 0,1025 & 0,0953 & 0,1075 \\
\hline & $(0,0161)$ & $(0,0109)$ & $(0,0076)$ & $(0,0071)$ & $(0,0046)$ \\
\hline \multirow[t]{2}{*}{ região Norte } & $-0,0813$ & $-0,0346$ & $-0,0177$ & $-0,0365$ & $-0,0354$ \\
\hline & $(0,0319)$ & $(0,0218)$ & $(0,0155)$ & $(0,0147)$ & $(0,0091)$ \\
\hline \multirow[t]{2}{*}{ região Nordeste } & $-0,1331$ & $-0,0581$ & $-0,0799$ & $-0,0668$ & $-0,0755$ \\
\hline & $(0,0245)$ & $(0,0167)$ & $(0,0122)$ & $(0,0119)$ & $(0,0072)$ \\
\hline \multirow[t]{2}{*}{ região Sudeste } & $-0,1133$ & $-0,0376$ & $-0,0451$ & $-0,0275$ & $-0,0459$ \\
\hline & $(0,0231)$ & $(0,0162)$ & $(0,0118)$ & $(0,0113)$ & $(0,0069)$ \\
\hline \multirow[t]{2}{*}{ região Sul } & $-0,1849$ & $-0,0905$ & $-0,0754$ & $-0,0694$ & $-0,0863$ \\
\hline & $(0,0327)$ & $(0,0217)$ & $(0,0135)$ & $(0,0129)$ & $(0,0087)$ \\
\hline \multirow[t]{2}{*}{ Branca } & 0,0741 & 0,0154 & 0,0106 & 0,0143 & 0,0186 \\
\hline & $(0,0180)$ & $(0,0115)$ & $(0,0081)$ & $(0,0080)$ & $(0,0050)$ \\
\hline \multirow[t]{2}{*}{ anos de estudo } & $-0,0350$ & $-0,0046$ & 0,0027 & 0,0039 & $-0,0003$ \\
\hline & $(0,0090)$ & $(0,0046)$ & $(0,0018)$ & $(0,0015)$ & $(0,0015)$ \\
\hline \multirow[t]{2}{*}{ idade que teve o filho } & $-0,0261$ & $-0,0119$ & 0,0013 & $-0,0303$ & $-0,0168$ \\
\hline & $(0,0165)$ & $(0,0094)$ & $(0,0088)$ & $(0,0144)$ & $(0,0038)$ \\
\hline \multirow{2}{*}{$\begin{array}{l}\text { quadrado da idade que } \\
\text { teve o filho }\end{array}$} & 0,0003 & 0,0002 & $-0,0001$ & 0,0006 & 0,0003 \\
\hline & $(0,0003)$ & $(0,0002)$ & $(0,0002)$ & $(0,0003)$ & $(0,0001)$ \\
\hline \multirow[t]{2}{*}{ Constante } & 4,9003 & 3,9351 & 3,5524 & 3,9421 & 3,8743 \\
\hline & $(0,4472)$ & $(0,1967)$ & $(0,1097)$ & $(0,1511)$ & $(0,0656)$ \\
\hline \multicolumn{6}{|l|}{ Equação de Seleção } \\
\hline \multirow[t]{2}{*}{ Gêmeos } & $-0,1685$ & 0,0161 & 0,0739 & 0,0386 & $-0,0077$ \\
\hline & $(0,0973)$ & $(0,0785)$ & $(0,0717)$ & $(0,0838)$ & $(0,0400)$ \\
\hline
\end{tabular}




\begin{tabular}{|c|c|c|c|c|c|}
\hline \multirow{2}{*}{$\begin{array}{l}\text { Logaritmo da Jornada } \\
\text { de Trabalho }\end{array}$} & \multicolumn{4}{|c|}{ Considerando-se apenas mães que tiveram filhos... } & \multirow[t]{2}{*}{ Total } \\
\hline & $\begin{array}{l}\text { Há } 2 \text { anos ou menos } \\
\text { (curto-prazo) }\end{array}$ & $\begin{array}{l}\text { Entre } 3 \text { e } 6 \\
\text { anos }\end{array}$ & $\begin{array}{l}\text { Entre } 7 \text { e } 12 \\
\text { anos }\end{array}$ & $\begin{array}{c}\text { Há } 13 \text { anos ou } \\
\text { mais (longo-prazo) }\end{array}$ & \\
\hline \multirow[t]{2}{*}{1992} & $-0,0339$ & $-0,0040$ & $-0,0625$ & $-0,0072$ & $-0,0483$ \\
\hline & $(0,0297)$ & $(0,0234)$ & $(0,0188)$ & $(0,0203)$ & $(0,0109)$ \\
\hline \multirow[t]{2}{*}{1993} & $-0,0464$ & $-0,0394$ & $-0,0461$ & $-0,0040$ & $-0,0454$ \\
\hline & $(0,0298)$ & $(0,0232)$ & $(0,0188)$ & $(0,0200)$ & $(0,0108)$ \\
\hline \multirow[t]{2}{*}{1995} & 0,0456 & 0,0473 & 0,0419 & 0,0633 & 0,0400 \\
\hline & $(0,0298)$ & $(0,0234)$ & $(0,0186)$ & $(0,0196)$ & $(0,0107)$ \\
\hline \multirow[t]{2}{*}{1996} & $-0,0054$ & $-0,0108$ & $-0,0564$ & 0,0041 & $-0,0209$ \\
\hline & $(0,0304)$ & $(0,0237)$ & $(0,0189)$ & $(0,0196)$ & $(0,0109)$ \\
\hline \multirow[t]{2}{*}{1997} & $-0,0278$ & 0,0305 & $-0,0216$ & 0,0086 & $-0,0043$ \\
\hline & $(0,0299)$ & $(0,0234)$ & $(0,0185)$ & $(0,0194)$ & $(0,0107)$ \\
\hline \multirow[t]{2}{*}{1998} & $-0,0243$ & 0,0229 & $-0,0309$ & 0,0228 & $-0,0037$ \\
\hline & $(0,0300)$ & $(0,0233)$ & $(0,0187)$ & $(0,0195)$ & $(0,0107)$ \\
\hline \multirow[t]{2}{*}{ região Metropolitana } & $-0,0765$ & $-0,0813$ & $-0,1050$ & $-0,0708$ & $-0,0768$ \\
\hline & $(0,0166)$ & $(0,0130)$ & $(0,0104)$ & $(0,0111)$ & $(0,0060)$ \\
\hline \multirow[t]{2}{*}{ região Norte } & 0,0246 & $-0,0197$ & 0,0274 & 0,0245 & 0,0270 \\
\hline & $(0,0371)$ & $(0,0288)$ & $(0,0229)$ & $(0,0238)$ & $(0,0131)$ \\
\hline \multirow[t]{2}{*}{ região Nordeste } & 0,0506 & 0,0060 & 0,0220 & $-0,0316$ & 0,0054 \\
\hline & $(0,0281)$ & $(0,0222)$ & $(0,0180)$ & $(0,0190)$ & $(0,0103)$ \\
\hline \multirow{2}{*}{ região Sudeste } & $-0,0152$ & $-0,0501$ & $-0,0624$ & $-0,0468$ & $-0,0304$ \\
\hline & $(0,0271)$ & $(0,0213)$ & $(0,0171)$ & $(0,0180)$ & $(0,0098)$ \\
\hline \multirow{2}{*}{ região Sul } & 0,2116 & 0,2222 & 0,1710 & 0,1274 & 0,1780 \\
\hline & $(0,0302)$ & $(0,0238)$ & $(0,0192)$ & $(0,0203)$ & $(0,0110)$ \\
\hline \multirow[t]{2}{*}{ Branca } & 0,0922 & 0,0813 & 0,0677 & 0,0640 & 0,0631 \\
\hline & $(0,0025)$ & $(0,0018)$ & $(0,0014)$ & $(0,0015)$ & $(0,0008)$ \\
\hline \multirow[t]{2}{*}{ anos de estudo } & $-0,0758$ & $-0,0587$ & $-0,0700$ & $-0,0926$ & $-0,0712$ \\
\hline & $(0,0182)$ & $(0,0142)$ & $(0,0114)$ & $(0,0120)$ & $(0,0065)$ \\
\hline \multirow[t]{2}{*}{ idade que teve o filho } & 0,0918 & 0,0334 & $-0,0142$ & $-0,0041$ & 0,0134 \\
\hline & $(0,0129)$ & $(0,0118)$ & $(0,0129)$ & $(0,0229)$ & $(0,0056)$ \\
\hline \multirow{2}{*}{$\begin{array}{l}\text { quadrado da idade que } \\
\text { teve o filho }\end{array}$} & $-0,0009$ & $-0,0001$ & 0,0007 & 0,0002 & $-0,0001$ \\
\hline & $(0,0002)$ & $(0,0002)$ & $(0,0003)$ & $(0,0006)$ & $(0,0001)$ \\
\hline \multirow[t]{2}{*}{ renda do não trabalho } & $-0,000046$ & $-0,000051$ & $-0,000065$ & $-0,000124$ & $-0,000053$ \\
\hline & $(0,000008)$ & $(0,000005)$ & $(0,000004)$ & $(0,000005)$ & $(0,000002)$ \\
\hline \multirow[t]{2}{*}{ Constante } & $-2,6216$ & $-1,3751$ & $-0,3458$ & $-0,0042$ & $-0,5958$ \\
\hline & $(0,1612)$ & $(0,1408)$ & $(0,1455)$ & $(0,2328)$ & $(0,0652)$ \\
\hline \multirow[t]{2}{*}{ Razão inversa de Mills } & $-0,6645$ & $-0,3291$ & $-0,1556$ & $-0,1560$ & $-0,2311$ \\
\hline & $(0,1525)$ & $(0,0914)$ & $(0,0424)$ & $(0,0405)$ & $(0,0397)$ \\
\hline número de observações & 27.575 & 42.279 & 64.374 & 57.665 & 191.893 \\
\hline Censuradas & 17.210 & 23.403 & 31.347 & 24.257 & 96.217 \\
\hline \multirow{3}{*}{$\begin{array}{l}\text { não censuradas } \\
n^{0} \text { de obs. de mães de } \\
\text { gêmeos não-censuradas } \\
\text { Wald chi2 }(\mathrm{k})\end{array}$} & 10.365 & 18.876 & 33.027 & 33.408 & 95.676 \\
\hline & 71 & 127 & 182 & 140 & 520 \\
\hline & $3.195,49$ & $3.439,34$ & $3.633,49$ & $2.291,75$ & $8.788,99$ \\
\hline Prob > chi2 & 0,0000 & 0,0000 & 0,0000 & 0,0000 & 0,0000 \\
\hline
\end{tabular}

Desvio padrão robusto entre parênteses. 
TABELA 8a - IMPACTO DA OCORRÊNCIA DE GËMEOS SOBRE O SALÁRIOHORA - PROCEDIMENTO DE HECKMAN - APENAS AS MÃES CASADAS

\begin{tabular}{|c|c|c|c|c|c|}
\hline \multirow{2}{*}{$\begin{array}{l}\text { Logaritmo do } \\
\text { Salário-Hora }\end{array}$} & \multicolumn{4}{|c|}{ Considerando-se apenas mães que tiveram filhos... } & \multirow[t]{2}{*}{ Total } \\
\hline & $\begin{array}{l}\text { Há } 2 \text { anos ou menos } \\
\text { (curto-prazo) }\end{array}$ & $\begin{array}{l}\text { Entre } 3 \text { e } 6 \\
\text { anos }\end{array}$ & $\begin{array}{l}\text { Entre } 7 \text { e } 12 \\
\text { anos }\end{array}$ & $\begin{array}{c}\text { Há } 13 \text { anos ou } \\
\text { mais (longo-prazo) }\end{array}$ & \\
\hline \multicolumn{6}{|l|}{ Equação Principal } \\
\hline \multirow[t]{2}{*}{ Gêmeos } & $-0,0816$ & 0,0415 & 0,1900 & 0,0606 & 0,1121 \\
\hline & $(0,4247)$ & $(0,3311)$ & $(0,1609)$ & $(0,2371)$ & $(0,1959)$ \\
\hline \multirow[t]{2}{*}{1992} & $-0,4079$ & $-0,3004$ & $-0,3419$ & $-0,2473$ & $-0,4353$ \\
\hline & $(0,1378)$ & $(0,1000)$ & $(0,0464)$ & $(0,0600)$ & $(0,0583)$ \\
\hline \multirow[t]{2}{*}{1993} & $-0,5515$ & $-0,3824$ & $-0,3856$ & $-0,3146$ & $-0,4777$ \\
\hline & $(0,1388)$ & $(0,0980)$ & $(0,0454)$ & $(0,0589)$ & $(0,0564)$ \\
\hline \multirow[t]{2}{*}{1995} & 0,1758 & 0,2393 & 0,1095 & 0,1946 & 0,1907 \\
\hline & $(0,1316)$ & $(0,0975)$ & $(0,0435)$ & $(0,0573)$ & $(0,0537)$ \\
\hline \multirow[t]{2}{*}{1996} & 0,0425 & 0,1361 & 0,0551 & 0,1528 & 0,0856 \\
\hline & $(0,1340)$ & $(0,0983)$ & $(0,0451)$ & $(0,0575)$ & $(0,0542)$ \\
\hline \multirow[t]{2}{*}{1997} & $-0,0673$ & 0,2101 & 0,0445 & 0,1317 & 0,0911 \\
\hline & $(0,1336)$ & $(0,0977)$ & $(0,0434)$ & $(0,0570)$ & $(0,0533)$ \\
\hline \multirow[t]{2}{*}{1998} & $-0,0445$ & 0,1855 & 0,0061 & 0,1403 & 0,0831 \\
\hline & $(0,1329)$ & $(0,0976)$ & $(0,0439)$ & $(0,0572)$ & $(0,0534)$ \\
\hline \multirow[t]{2}{*}{ região Metropolitana } & 0,1706 & 0,1475 & 0,1262 & 0,1607 & 0,1285 \\
\hline & $(0,0738)$ & $(0,0542)$ & $(0,0255)$ & $(0,0324)$ & $(0,0304)$ \\
\hline \multirow[t]{2}{*}{ região Norte } & $-0,1212$ & $-0,1402$ & $-0,0193$ & $-0,0778$ & $-0,0450$ \\
\hline & $(0,1718)$ & $(0,1254)$ & $(0,0542)$ & $(0,0697)$ & $(0,0665)$ \\
\hline \multirow[t]{2}{*}{ região Nordeste } & $-0,3429$ & $-0,3895$ & $-0,3363$ & $-0,4186$ & $-0,3975$ \\
\hline & $(0,1279)$ & $(0,0938)$ & $(0,0427)$ & $(0,0566)$ & $(0,0522)$ \\
\hline \multirow[t]{2}{*}{ região Sudeste } & $-0,0362$ & $-0,0646$ & $-0,0846$ & $-0,0496$ & $-0,0421$ \\
\hline & $(0,1216)$ & $(0,0897)$ & $(0,0408)$ & $(0,0530)$ & $(0,0494)$ \\
\hline \multirow[t]{2}{*}{ região Sul } & 0,4963 & 0,5169 & 0,1563 & 0,1713 & 0,4596 \\
\hline & $(0,1659)$ & $(0,1252)$ & $(0,0495)$ & $(0,0606)$ & $(0,0690)$ \\
\hline \multirow[t]{2}{*}{ Branca } & $-0,0882$ & 0,0154 & 0,0468 & $-0,0626$ & $-0,0881$ \\
\hline & $(0,0937)$ & $(0,0640)$ & $(0,0295)$ & $(0,0386)$ & $(0,0392)$ \\
\hline \multirow[t]{2}{*}{ anos de estudo } & 0,4235 & 0,3641 & 0,2349 & 0,2269 & 0,3467 \\
\hline & $(0,0513)$ & $(0,0350)$ & $(0,0113)$ & $(0,0090)$ & $(0,0192)$ \\
\hline \multirow[t]{2}{*}{ idade que teve o filho } & 0,4413 & 0,1270 & $-0,0117$ & $-0,0428$ & 0,0303 \\
\hline & $(0,0873)$ & $(0,0517)$ & $(0,0305)$ & $(0,0671)$ & $(0,0276)$ \\
\hline \multirow{2}{*}{$\begin{array}{l}\text { quadrado da idade que } \\
\text { teve o filho }\end{array}$} & $-0,0055$ & $-0,0008$ & 0,0011 & 0,0014 & 0,0003 \\
\hline & $(0,0014)$ & $(0,0010)$ & $(0,0007)$ & $(0,0016)$ & $(0,0006)$ \\
\hline \multirow[t]{2}{*}{ Constante } & $-13,4762$ & $-7,4777$ & $-2,1330$ & $-1,6245$ & $-5,8339$ \\
\hline & $(2,3619)$ & $(1,2591)$ & $(0,4485)$ & $(0,7172)$ & $(0,6382)$ \\
\hline \multicolumn{6}{|l|}{ Equação de Seleção } \\
\hline \multirow[t]{2}{*}{ Gêmeos } & $-0,0817$ & $-0,0005$ & 0,0862 & 0,0622 & 0,0206 \\
\hline & $(0,1027)$ & $(0,0854)$ & $(0,0751)$ & $(0,0887)$ & $(0,0426)$ \\
\hline
\end{tabular}




\begin{tabular}{|c|c|c|c|c|c|}
\hline \multirow{2}{*}{$\begin{array}{l}\text { Logaritmo do } \\
\text { Salário-Hora }\end{array}$} & \multicolumn{4}{|c|}{ Considerando-se apenas mães que tiveram filhos... } & \multirow[t]{2}{*}{ Total } \\
\hline & $\begin{array}{l}\text { Há } 2 \text { anos ou menos } \\
\text { (curto-prazo) }\end{array}$ & $\begin{array}{l}\text { Entre } 3 \text { e } 6 \\
\text { anos }\end{array}$ & $\begin{array}{l}\text { Entre } 7 \text { e } 12 \\
\text { anos }\end{array}$ & $\begin{array}{l}\text { Há } 13 \text { anos ou } \\
\text { mais (longo-prazo) }\end{array}$ & \\
\hline \multirow[t]{2}{*}{1992} & $-0,0791$ & $-0,0482$ & $-0,0853$ & $-0,0348$ & $-0,0743$ \\
\hline & $(0,0315)$ & $(0,0250)$ & $(0,0201)$ & $(0,0219)$ & $(0,0117)$ \\
\hline \multirow[t]{2}{*}{1993} & $-0,0860$ & $-0,0408$ & $-0,0648$ & $-0,0146$ & $-0,0576$ \\
\hline & $(0,0316)$ & $(0,0247)$ & $(0,0201)$ & $(0,0216)$ & $(0,0116)$ \\
\hline \multirow[t]{2}{*}{1995} & 0,0269 & 0,0401 & 0,0285 & 0,0554 & 0,0303 \\
\hline & $(0,0315)$ & $(0,0248)$ & $(0,0198)$ & $(0,0212)$ & $(0,0115)$ \\
\hline \multirow[t]{2}{*}{1996} & $-0,0124$ & 0,0031 & $-0,0466$ & 0,0296 & $-0,0087$ \\
\hline & $(0,0321)$ & $(0,0252)$ & $(0,0202)$ & $(0,0213)$ & $(0,0116)$ \\
\hline \multirow[t]{2}{*}{1997} & $-0,0350$ & 0,0437 & $-0,0097$ & 0,0205 & 0,0043 \\
\hline & $(0,0316)$ & $(0,0248)$ & $(0,0198)$ & $(0,0211)$ & $(0,0115)$ \\
\hline \multirow[t]{2}{*}{1998} & $-0,0293$ & 0,0371 & $-0,0181$ & 0,0441 & 0,0082 \\
\hline & $(0,0317)$ & $(0,0248)$ & $(0,0200)$ & $(0,0212)$ & $(0,0115)$ \\
\hline \multirow[t]{2}{*}{ região Metropolitana } & $-0,0144$ & $-0,0138$ & $-0,0444$ & $-0,0033$ & $-0,0187$ \\
\hline & $(0,0175)$ & $(0,0138)$ & $(0,0111)$ & $(0,0120)$ & $(0,0064)$ \\
\hline \multirow[t]{2}{*}{ região Norte } & $-0,0159$ & $-0,0664$ & 0,0040 & $-0,0294$ & $-0,0095$ \\
\hline & $(0,0402)$ & $(0,0310)$ & $(0,0245)$ & $(0,0258)$ & $(0,0142)$ \\
\hline \multirow[t]{2}{*}{ região Nordeste } & 0,0220 & $-0,0170$ & 0,0029 & $-0,0676$ & $-0,0184$ \\
\hline & $(0,0301)$ & $(0,0238)$ & $(0,0193)$ & $(0,0208)$ & $(0,0111)$ \\
\hline \multirow[t]{2}{*}{ região Sudeste } & $-0,0049$ & $-0,0277$ & $-0,0378$ & $-0,0262$ & $-0,0110$ \\
\hline & $(0,0288)$ & $(0,0227)$ & $(0,0183)$ & $(0,0196)$ & $(0,0106)$ \\
\hline \multirow[t]{2}{*}{ região Sul } & 0,2025 & 0,2025 & 0,1382 & 0,1013 & 0,1566 \\
\hline & $(0,0320)$ & $(0,0252)$ & $(0,0205)$ & $(0,0219)$ & $(0,0118)$ \\
\hline \multirow{2}{*}{ Branca } & 0,1074 & 0,0932 & 0,0775 & 0,0730 & 0,0743 \\
\hline & $(0,0027)$ & $(0,0020)$ & $(0,0015)$ & $(0,0017)$ & $(0,0009)$ \\
\hline \multirow{2}{*}{ anos de estudo } & $-0,0787$ & $-0,0516$ & $-0,0695$ & $-0,0954$ & $-0,0714$ \\
\hline & $(0,0194)$ & $(0,0151)$ & $(0,0122)$ & $(0,0130)$ & $(0,0070)$ \\
\hline \multirow[t]{2}{*}{ idade que teve o filho } & 0,1001 & 0,0212 & $-0,0148$ & $-0,0146$ & 0,0034 \\
\hline & $(0,0139)$ & $(0,0126)$ & $(0,0138)$ & $(0,0248)$ & $(0,0060)$ \\
\hline \multirow{2}{*}{$\begin{array}{l}\text { quadrado da idade que } \\
\text { teve o filho }\end{array}$} & $-0,0011$ & 0,0001 & 0,0007 & 0,0004 & 0,0001 \\
\hline & $(0,0003)$ & $(0,0003)$ & $(0,0003)$ & $(0,0006)$ & $(0,0001)$ \\
\hline \multirow[t]{2}{*}{ renda do não trabalho } & $-0,000044$ & $-0,000043$ & $-0,000041$ & $-0,000102$ & $-0,000034$ \\
\hline & $(0,000008)$ & $(0,000006)$ & $(0,000004)$ & $(0,000005)$ & $(0,000003)$ \\
\hline \multirow[t]{2}{*}{ Constante } & $-2,9873$ & $-1,4879$ & $-0,6064$ & $-0,2154$ & $-0,7953$ \\
\hline & $(0,1738)$ & $(0,1507)$ & $(0,1557)$ & $(0,2525)$ & $(0,0701)$ \\
\hline \multirow[t]{2}{*}{ Razão inversa de Mills } & 4,2330 & 4,0163 & 2,3125 & 2,9044 & 4,8485 \\
\hline & $(0,7229)$ & $(0,5778)$ & $(0,2288)$ & $(0,2108)$ & $(0,4034)$ \\
\hline \multirow{2}{*}{$\begin{array}{l}\text { número de observações } \\
\text { censuradas }\end{array}$} & 26.036 & 39.006 & 57.451 & 48.698 & 171.191 \\
\hline & 17.452 & 24.098 & 32.580 & 25.176 & 99.306 \\
\hline \multirow{3}{*}{$\begin{array}{l}\quad \text { não censuradas } \\
n^{0} \text { de obs. de mães de } \\
\text { gêmeos não-censuradas } \\
\text { Wald chi2 }(k)\end{array}$} & 8.584 & 14.908 & 24.871 & 23.522 & 71.885 \\
\hline & 64 & 95 & 145 & 105 & 409 \\
\hline & 3390,83 & 3575,57 & 4431,56 & 3019,79 & 9619,54 \\
\hline Prob > chi2 & 0,0000 & 0,0000 & 0,0000 & 0,0000 & 0,0000 \\
\hline
\end{tabular}

Desvio padrão robusto entre parênteses. 
TABELA 8b - IMPACTO DA OCORRÊNCIA DE GÊMEOS SOBRE O SALÁRIOHORA - PROCEDIMENTO DE HECKMAN - TODAS AS MÃES

\begin{tabular}{|c|c|c|c|c|c|}
\hline \multirow{2}{*}{$\begin{array}{l}\text { Logaritmo do } \\
\text { salário-hora }\end{array}$} & \multicolumn{4}{|c|}{ Considerando-se apenas mães que tiveram filhos... } & \multirow[t]{2}{*}{ Total } \\
\hline & $\begin{array}{l}\text { Há } 2 \text { anos ou menos } \\
\text { (curto-prazo) }\end{array}$ & $\begin{array}{c}\text { Entre } 3 \text { e } 6 \\
\text { anos }\end{array}$ & $\begin{array}{c}\text { Entre } 7 \text { e } 12 \\
\text { anos }\end{array}$ & $\begin{array}{c}\text { Há } 13 \text { anos ou } \\
\text { mais (longo-prazo) }\end{array}$ & \\
\hline \multicolumn{6}{|l|}{ Equação Principal } \\
\hline \multirow[t]{2}{*}{ Gêmeos } & $-0,1937$ & 0,0864 & 0,1172 & $-0,0311$ & 0,0368 \\
\hline & $(0,3194)$ & $(0,1868)$ & $(0,0696)$ & $(0,1308)$ & $(0,0726)$ \\
\hline \multirow[t]{2}{*}{1992} & $-0,3506$ & $-0,2308$ & $-0,2682$ & $-0,1994$ & $-0,2856$ \\
\hline & $(0,1011)$ & $(0,0573)$ & $(0,0193)$ & $(0,0322)$ & $(0,0204)$ \\
\hline \multirow[t]{2}{*}{1993} & $-0,5034$ & $-0,3447$ & $-0,3295$ & $-0,2959$ & $-0,3674$ \\
\hline & $(0,1023)$ & $(0,0568)$ & $(0,0192)$ & $(0,0316)$ & $(0,0201)$ \\
\hline \multirow[t]{2}{*}{1995} & 0,1651 & 0,1871 & 0,0873 & 0,1716 & 0,1395 \\
\hline & $(0,0979)$ & $(0,0565)$ & $(0,0186)$ & $(0,0308)$ & $(0,0196)$ \\
\hline \multirow[t]{2}{*}{1996} & 0,0512 & 0,1377 & 0,0853 & 0,1412 & 0,1048 \\
\hline & $(0,0999)$ & $(0,0572)$ & $(0,0191)$ & $(0,0308)$ & $(0,0199)$ \\
\hline \multirow[t]{2}{*}{1997} & $-0,0231$ & 0,1889 & 0,0537 & 0,1187 & 0,0917 \\
\hline & $(0,0986)$ & $(0,0565)$ & $(0,0186)$ & $(0,0305)$ & $(0,0195)$ \\
\hline \multirow[t]{2}{*}{1998} & $-0,0100$ & 0,1467 & 0,0222 & 0,1240 & 0,0757 \\
\hline & $(0,0984)$ & $(0,0564)$ & $(0,0187)$ & $(0,0305)$ & $(0,0195)$ \\
\hline \multirow[t]{2}{*}{ região Metropolitana } & 0,1936 & 0,1908 & 0,1869 & 0,2063 & 0,2017 \\
\hline & $(0,0546)$ & $(0,0314)$ & $(0,0105)$ & $(0,0174)$ & $(0,0110)$ \\
\hline \multirow[t]{2}{*}{ região Norte } & $-0,1303$ & $-0,0808$ & $-0,0450$ & $-0,0801$ & $-0,0558$ \\
\hline & $(0,1255)$ & $(0,0711)$ & $(0,0232)$ & $(0,0372)$ & $(0,0242)$ \\
\hline \multirow[t]{2}{*}{ região Nordeste } & $-0,4069$ & $-0,4014$ & $-0,3397$ & $-0,4075$ & $-0,3906$ \\
\hline & $(0,0938)$ & $(0,0541)$ & $(0,0181)$ & $(0,0300)$ & $(0,0190)$ \\
\hline \multirow[t]{2}{*}{ região Sudeste } & $-0,0766$ & $-0,0782$ & $-0,0462$ & $-0,0578$ & $-0,0446$ \\
\hline & $(0,0902)$ & $(0,0522)$ & $(0,0173)$ & $(0,0283)$ & $(0,0181)$ \\
\hline \multirow[t]{2}{*}{ região Sul } & 0,3152 & 0,2609 & 0,0280 & 0,0398 & 0,1142 \\
\hline & $(0,1113)$ & $(0,0628)$ & $(0,0194)$ & $(0,0318)$ & $(0,0208)$ \\
\hline \multirow[t]{2}{*}{ Branca } & $-0,0552$ & 0,0611 & 0,1106 & 0,0175 & 0,0506 \\
\hline & $(0,0688)$ & $(0,0368)$ & $(0,0119)$ & $(0,0199)$ & $(0,0129)$ \\
\hline \multirow[t]{2}{*}{ anos de estudo } & 0,3417 & 0,2630 & 0,1654 & 0,1772 & 0,2027 \\
\hline & $(0,0298)$ & $(0,0135)$ & $(0,0024)$ & $(0,0035)$ & $(0,0034)$ \\
\hline \multirow[t]{2}{*}{ idade que teve o filho } & 0,3477 & 0,0872 & $-0,0056$ & $-0,0275$ & 0,0090 \\
\hline & $(0,0589)$ & $(0,0292)$ & $(0,0131)$ & $(0,0360)$ & $(0,0101)$ \\
\hline \multirow{2}{*}{$\begin{array}{l}\text { quadrado da idade que } \\
\text { teve o filho }\end{array}$} & $-0,0042$ & $-0,0005$ & 0,0007 & 0,0009 & 0,0003 \\
\hline & $(0,0010)$ & $(0,0006)$ & $(0,0003)$ & $(0,0009)$ & $(0,0002)$ \\
\hline \multirow[t]{2}{*}{ Constante } & $-10,1896$ & $-4,3436$ & $-0,3204$ & $-0,3835$ & $-1,5929$ \\
\hline & $(1,4601)$ & $(0,5497)$ & $(0,1576)$ & $(0,3749)$ & $(0,1491)$ \\
\hline \multicolumn{6}{|l|}{ Equação de Seleção } \\
\hline \multirow[t]{2}{*}{ Gêmeos } & $-0,1374$ & 0,0426 & 0,0786 & 0,0278 & 0,0051 \\
\hline & $(0,0981)$ & $(0,0792)$ & $(0,0717)$ & $(0,0832)$ & $(0,0402)$ \\
\hline \multirow[t]{2}{*}{1992} & $-0,0726$ & $-0,0369$ & $-0,0876$ & $-0,0319$ & $-0,0752$ \\
\hline & $(0,0303)$ & $(0,0237)$ & $(0,0189)$ & $(0,0202)$ & $(0,0109)$ \\
\hline
\end{tabular}




\begin{tabular}{|c|c|c|c|c|c|}
\hline \multirow{2}{*}{$\begin{array}{l}\text { Logaritmo do } \\
\text { salário-hora }\end{array}$} & \multicolumn{4}{|c|}{ Considerando-se apenas mães que tiveram filhos... } & \multirow[t]{2}{*}{ Total } \\
\hline & $\begin{array}{l}\text { Há } 2 \text { anos ou menos } \\
\text { (curto-prazo) }\end{array}$ & $\begin{array}{c}\text { Entre } 3 \text { e } 6 \\
\text { anos }\end{array}$ & $\begin{array}{c}\text { Entre } 7 \text { e } 12 \\
\text { anos }\end{array}$ & $\begin{array}{c}\text { Há } 13 \text { anos ou } \\
\text { mais (longo-prazo) }\end{array}$ & \\
\hline \multirow[t]{2}{*}{1993} & $-0,0882$ & $-0,0434$ & $-0,0737$ & $-0,0223$ & $-0,0653$ \\
\hline & $(0,0304)$ & $(0,0235)$ & $(0,0189)$ & $(0,0199)$ & $(0,0109)$ \\
\hline \multirow[t]{2}{*}{1995} & 0,0359 & 0,0323 & 0,0313 & 0,0575 & 0,0308 \\
\hline & $(0,0302)$ & $(0,0236)$ & $(0,0187)$ & $(0,0195)$ & $(0,0108)$ \\
\hline \multirow[t]{2}{*}{1996} & $-0,0137$ & 0,0036 & $-0,0500$ & 0,0278 & $-0,0093$ \\
\hline & $(0,0308)$ & $(0,0239)$ & $(0,0189)$ & $(0,0195)$ & $(0,0109)$ \\
\hline \multirow[t]{2}{*}{1997} & $-0,0229$ & 0,0507 & $-0,0113$ & 0,0185 & 0,0069 \\
\hline & $(0,0303)$ & $(0,0236)$ & $(0,0186)$ & $(0,0193)$ & $(0,0107)$ \\
\hline \multirow[t]{2}{*}{1998} & $-0,0198$ & 0,0363 & $-0,0192$ & 0,0426 & 0,0097 \\
\hline & $(0,0304)$ & $(0,0235)$ & $(0,0187)$ & $(0,0194)$ & $(0,0108)$ \\
\hline \multirow[t]{2}{*}{ região Metropolitana } & $-0,0034$ & $-0,0013$ & $-0,0224$ & 0,0238 & 0,0049 \\
\hline & $(0,0168)$ & $(0,0131)$ & $(0,0104)$ & $(0,0110)$ & $(0,0060)$ \\
\hline \multirow[t]{2}{*}{ região Norte } & $-0,0247$ & $-0,0600$ & $-0,0246$ & $-0,0380$ & $-0,0232$ \\
\hline & $(0,0380)$ & $(0,0292)$ & $(0,0230)$ & $(0,0237)$ & $(0,0132)$ \\
\hline \multirow[t]{2}{*}{ região Nordeste } & $-0,0124$ & $-0,0363$ & $-0,0372$ & $-0,0904$ & $-0,0483$ \\
\hline & $(0,0286)$ & $(0,0225)$ & $(0,0180)$ & $(0,0190)$ & $(0,0104)$ \\
\hline \multirow[t]{2}{*}{ região Sudeste } & $-0,0300$ & $-0,0533$ & $-0,0680$ & $-0,0448$ & $-0,0347$ \\
\hline & $(0,0275)$ & $(0,0215)$ & $(0,0171)$ & $(0,0180)$ & $(0,0099)$ \\
\hline \multirow[t]{2}{*}{ região Sul } & 0,1689 & 0,1727 & 0,0969 & 0,0659 & 0,1185 \\
\hline & $(0,0306)$ & $(0,0240)$ & $(0,0192)$ & $(0,0202)$ & $(0,0111)$ \\
\hline \multirow[t]{2}{*}{ Branca } & 0,1022 & 0,0901 & 0,0773 & 0,0735 & 0,0726 \\
\hline & $(0,0025)$ & $(0,0019)$ & $(0,0014)$ & $(0,0015)$ & $(0,0008)$ \\
\hline \multirow[t]{2}{*}{ anos de estudo } & $-0,0877$ & $-0,0668$ & $-0,0800$ & $-0,0984$ & $-0,0800$ \\
\hline & $(0,0186)$ & $(0,0143)$ & $(0,0114)$ & $(0,0120)$ & $(0,0066)$ \\
\hline \multirow[t]{2}{*}{ idade que teve o filho } & 0,1004 & 0,0194 & $-0,0181$ & $-0,0139$ & 0,0031 \\
\hline & $(0,0132)$ & $(0,0120)$ & $(0,0130)$ & $(0,0228)$ & $(0,0056)$ \\
\hline \multirow{2}{*}{$\begin{array}{l}\text { quadrado da idade que } \\
\text { teve o filho }\end{array}$} & $-0,0010$ & 0,0002 & 0,0008 & 0,0004 & 0,0001 \\
\hline & $(0,0003)$ & $(0,0002)$ & $(0,0003)$ & $(0,0006)$ & $(0,0001)$ \\
\hline \multirow[t]{2}{*}{ renda do não trabalho } & $-0,000067$ & $-0,000070$ & $-0,000091$ & $-0,000154$ & $-0,000077$ \\
\hline & $(0,000008)$ & $(0,000006)$ & $(0,000004)$ & $(0,000005)$ & $(0,000002)$ \\
\hline \multirow[t]{2}{*}{ Constante } & $-2,8801$ & $-1,3631$ & $-0,4520$ & $-0,0572$ & $-0,6337$ \\
\hline & $(0,1655)$ & $(0,1426)$ & $(0,1463)$ & $(0,2321)$ & $(0,0656)$ \\
\hline \multirow[t]{2}{*}{ Razão inversa de Mills } & 3,3058 & 2,4899 & 0,9030 & 1,7397 & 1,9329 \\
\hline & $(0,4513)$ & $(0,2349)$ & $(0,0459)$ & $(0,0799)$ & $(0,0725)$ \\
\hline número de observações & 27.575 & 42.279 & 64.374 & 57.665 & 191.893 \\
\hline censuradas & 17.999 & 25.009 & 34.197 & 27.209 & 104.414 \\
\hline não censuradas & 9.576 & 17.270 & 30.177 & 30.456 & 87.479 \\
\hline $\begin{array}{l}n^{0} \text { de obs. de mães de } \\
\text { gêmeos não-censuradas }\end{array}$ & 69 & 119 & 169 & 127 & 484 \\
\hline Wald chi2 (k) & $3.670,01$ & $4.387,94$ & $12.598,24$ & $6.356,35$ & $16.393,6$ \\
\hline Prob > chi2 & 0,0000 & 0,0000 & 0,0000 & 0,0000 & 0,0000 \\
\hline
\end{tabular}

Desvio padrão robusto entre parênteses. 
Como pode ser visto nas Tabelas 7a e 7b, o efeito positivo de curto prazo do filho a mais sobre a jornada de trabalho continua existindo. As estimativas indicam que mães de gêmeos têm jornadas, aproximadamente, $17 \%$ maiores do que mães de não-gêmeos. Esse resultado vale tanto para a amostra de mães casadas quanto para a amostra de todas as mães. Ou seja, mães de gêmeos que ficam no mercado trabalham mais do que mães de não-gêmeos. Este impacto é inclusive maior do que o encontrado via mínimos quadrados, algo evidenciado pela razão de Mills, que diferentemente do esperado tem sinal negativo. Para os outros momentos do tempo, os coeficientes não são estatisticamente diferentes de zero, indicando que tal diferencial tende a desaparecer. Deve ser colocado, no entanto, que talvez a renda do não-trabalho não seja um bom instrumento quando a variável de interesse é a jornada de trabalho (embora o sinal da variável na equação de seleção tenha apresentado o sinal esperado) e, desta forma, ainda estejamos diante de um coeficiente enviesado.

Para as outras variáveis explicativas, os resultados indicam que mães que moram em áreas metropolitanas, na região Centro-Oeste e que são brancas têm maiores jornadas relativamente aos seus respectivos grupos de comparação. Quanto às dummies de anos, para a maioria dos modelos, as jornadas entre os anos de 1992 e 1995 são menores do que as de 1999, não havendo diferença entre os anos de 1996 a 1998 e o ano de 1999. Para a variável anos de estudo o resultado é interessante: mulheres mais educadas tendem a trabalhar menos no curto prazo, logo após o nascimento do filho. No entanto, no longo prazo, quando já se passaram 13 anos após o nascimento do filho, quanto mais educadas as mulheres, maiores serão as jornadas de trabalho. Por fim, as variáveis 'idade em que teve o filho' e 'idade em que teve o filho ao quadrado', embora estatisticamente significativas apenas nos modelos quando não se considera o tempo após o nascimento do filho (últimas colunas), na maioria dos casos indicam que o impacto da idade inicialmente é negativo e depois positivo.

Por fim, os resultados obtidos para o salário-hora. Para esta variável, a maioria dos coeficientes associados à dummy gêmeos não foi estatisticamente diferente de zero, ${ }^{18}$ o que significa, a princípio, que não existem diferenciais de salário-hora entre mães de gêmeos e mães de não-gêmeos. A razão de Mills apresentou, neste caso, o sinal esperado, indicando que as características que determinam a seleção são positivamente correlacionadas com o salário-hora. A princípio não é possível afirmar que as estimativas via Heckman tenham corrigido o viés de seleção, embora o fato da razão de Mills ter sido estatisticamente significativa em todos modelos pareça apontar para a existência de viés.

18 O coeficiente associado à dummy gêmeos mostrou-se estatisticamente significativo em apenas um caso: para a amostra de todas as mães, quando focamos o período de 7 a 12 anos após o nascimento do filho, indicando um diferencial positivo a favor das mães de gêmeos. 
Para os demais controles, vale destacar alguns resultados. Com relação às dummies de ano, para a maioria dos casos, têm-se salários-hora menores em 1992 e 1993 relativamente a 1999, mas salários-hora maiores a partir de 1995 relativamente a 1999. A dummy para cor 'branca' não foi estatisticamente diferente de zero na maior parte dos casos. Mães moradoras em regiões metropolitanas ganham maiores salários-hora; com relação às macrorregiões, os resultados indicam que as mães no Nordeste recebem salários-hora menores que as do Centro-Oeste; que as do Sul recebem salários-hora maiores que as do Centro-Oeste; e que não há diferenças salariais, condicionais nas outras variáveis, entre as regiôes Norte, Sudeste e Centro-Oeste. Os coeficientes associados à variável 'idade em que teve o filho' são positivos e estatisticamente significativos apenas no período até 6 anos do nascimento do filho; já para a variável 'idade em que teve o filho ao quadrado', os coeficientes são estatisticamente diferentes de zero no curto prazo (até 2 anos do nascimento) e no período entre 7 e 12 anos do nascimento do filho, sendo negativos no primeiro período e positivos no segundo período. O resultado para a escolaridade é o já esperado, ou seja, quanto maior a escolaridade, maior o salário-hora.

Em suma, de acordo com os resultados obtidos, no curto prazo o filho não planejado faz com que as mães que permaneçam no mercado de trabalho trabalhem mais, embora estas não recebam maiores salários-hora por isso. No longo prazo, não existem mais diferenças entre mães de gêmeos e não-gêmeos, tanto no que se refere à jornada de trabalho quanto ao salário-hora, ou seja, a saída do mercado de trabalho observada no curto prazo em razão do filho não-planejado não afeta o engajamento e os rendimentos futuros.

\section{CONSIDERAÇÕES FINAIS}

O objetivo deste artigo foi analisar o impacto de um choque exógeno na fecundidade - ocorrência de gêmeos na primeira gravidez - sobre o engajamento da mulher na força de trabalho. A hipótese assumida de que esta variação seja de fato exógena resolve o problema de endogeneidade existente na relação entre a oferta de trabalho da mulher e o número de filhos. Este exercício já foi realizado por outros autores para os Estados Unidos. A contribuição deste artigo, além do fato de usar dados para o Brasil, está em chamar atenção para um possível viés de seleção que pode surgir na análise das variáveis de mercado de trabalho (salário e jornada de trabalho).

Os resultados obtidos mostram que, primeiro, um aumento não-planejado no número de filhos tem efeito negativo apenas sobre a probabilidade de participação da mulher no mercado de trabalho e, segundo, que este impacto negativo é apenas de curto prazo. Para as que trabalham, não foram encontradas evidências de que o filho não- 
planejado afete nem o salário e nem as horas trabalhadas no longo prazo. Entretanto, no curto prazo, os resultados obtidos para jornada de trabalho e salário-hora aparentemente são contraditórios, indicando que possivelmente exista uma seleção quando as variáveis de mercado de trabalho são analisadas.

\section{REFERÊNCIAS BIBLIOGRÁFICAS}

Angrist, J. D.; Evans, W. N. Children and their parents' labor supply: evidence from exogenous variation in family size. The American EconomicReview, v. 88, n. 3, 1998.

Bronars, S. G.; Grogger, J. The economic consequences of unwed motherhood: using twin births as a natural experiment. The American Economic Review, v. 84, n. $5,1994$.

Gangadharan, J.; Rosenbloom, J. L. The effects of child-bearing on married women's labor supply and earnings: using twin births as a natural experiment. NBER Working Paper Series, ${ }^{\circ}$ 5647. Cambridge, MA, 1996.

Heckman, J. J. Sample selection bias as a specification error. Econometrica, v. 47, n. 1, 1979.

Killingsworth, M. R.; Heckman, J. J. Female labor supply: a survey. In: Ashenfelter, Orley; Layard, Richard (eds.), Handbook of labor economics, v. 1, 1986.

Rosenzweig, M. R.; Wolpin, K. I. Testing the quantity-quality fertility model: the use of twins as a natural experiment. Econometrica, v. 48, n. 1, 1980a.

. Life-cycle labor supply and fertility: causal inferences from household models. Journal of Political Economy, v. 88, n. 2, 1980 b.

Scorzafave, L. G.; Menezes-Filho, N. A. Participação feminina no mercado de trabalho brasileiro: evolução e determinantes. Pesquisa e Planejamento Econômico, Rio de Janeiro, v. 31, n. 3, p. 441-478, 2001.

Soares, S.; Izaki, R. S. A participação feminina no mercado de trabalho. Texto para Discussão do IPEA, n. 293. Rio de Janeiro, 2002. 